\title{
Surface Properties and Mechanical Performance of Ti-Based Dental Materials: Comparative Effect of Valve Alloying Elements and Structural Defects
}

\author{
AGATA SOTNICZUK, KAMIL MAJCHROWICZ, DONATA KUCZYŃSKA-ZEMŁA, \\ MARCIN PISAREK, BOGUSŁAWA ADAMCZYK-CIEŚLAK, \\ and HALINA GARBACZ
}

\begin{abstract}
Two approaches can be taken when designing properties of the native oxide layers formed on Ti-based biomedical materials: (i) changing the chemical composition of the substrate by adding biocompatible, valve alloying elements, and (ii) changing the microstructure of the substrateespecially its level of defectiveness - through large plastic deformation. However, especially in the aggressive fluoridated oral environment, it is still unknown what factor is more effective in terms of enhancing oxide layer protectiveness against biocorrosion: (i) the presence of valve alloying elements, or (ii) a high number of structural defects. To gain knowledge about the separate influence of both of these factors, surface properties were examined for commercially pure $\mathrm{Ti}$ and $\mathrm{Ti}-\mathrm{Nb}-\mathrm{Ta}-\mathrm{Zr}$ alloy in microcrystalline state as well as after multiple-pass cold rolling, a process that can be readily scaled up to the industrial level. This study showed that while valve-alloying elements and structural defects individually have a beneficial effect on $\mathrm{Ti}$ oxide layer properties in fluoridated medium, they not have to act in a synergistic manner. These findings have to be taken into account when designing future Ti-based dental materials together with analyzing their mechanical performance with respect to mechanical strength and elastic properties.
\end{abstract}

https://doi.org/10.1007/s11661-021-06515-y

(c) The Author(s) 2021

\section{INTRODUCTION}

BIOMATERIAL candidates for long-lasting dental implantology must demonstrate a combination of low elastic modulus, ${ }^{[1-4]}$ biocompatibility ${ }^{[5-7]}$ and corrosion resistance ${ }^{[8-10]}$ when exposed to the various organic and inorganic substances present in the human body. Meeting these requirements are Ti-based materials that lack potentially toxic elements such as commercially pure $\alpha$ $\mathrm{Ti}(\mathrm{CP}-\mathrm{Ti})^{[11,12]}$ and metastable $\beta \mathrm{Ti}$ alloys with ultra-low elastic modulus that are currently under development. ${ }^{[3,13-15]}$ Quaternary Ti-Nb-Ta-Zr (TNTZ) alloys have great potential as they offer a remarkably low elastic modulus value, stable even during plastic

AGATA SOTNICZUK, KAMIL MAJCHROWICZ, DONATA KUCZYŃSKA-ZEMŁA, BOGUSŁAWA ADAMCZYK-CIEŚLAK, and HALINA GARBACZ are with the Faculty of Materials Science and Engineering, Warsaw University of Technology, Wołoska 141, 02 507 Warsaw, Poland. Contact e-mail: agata.sotniczuk.dokt@pw.edu.pl MARCIN PISAREK is with the Institute of Physical Chemistry, Polish Academy of Sciences, Kasprzaka 44/52, 01-224 Warsaw, Poland.

Manuscript submitted March 16, 2021; accepted October 25, 2021.

Article published online November 15, 2021 deformation and the finishing treatments involved in the manufacturing of implantable products..$^{[7,16,17]}$

However, CP-Ti and TNTZ alloys demonstrate insufficient mechanical strength to be used in load-bearing applications such as narrow dental implants, which are an integral part of modern dentistry. ${ }^{[11,18,19]}$ This drawback can be overcome by dislocation and grain boundary strengthening, achievable through large plastic deformation methods. ${ }^{[2-24]}$ Techniques based on typical methods of deformation, such as multiple-stage cold rolling, are of particular interest as they can be scaled up to the industrial level. ${ }^{[6,25-27]}$ The huge number of grain boundaries and dislocations introduced during large plastic deformation affect the material's mechanical properties as well as functional features such as corrosion resistance. ${ }^{[20,28,29]}$ It is well known that the high corrosion resistance of $\mathrm{Ti}$ and its alloys is governed by the presence of a nanometric protective oxide layer on their surfaces. ${ }^{[30]}$ The protective properties of $\mathrm{Ti}$ oxide layers against corrosion attack depend on the microstructure of the substrate material. ${ }^{[31,32]}$ Grain boundaries and dislocations are the preferential oxidation sites, so their high number in deformed Ti provides more stable oxide layers, thereby demonstrating their enhanced propensity for repassivation in the case of 
local disruption. ${ }^{[20]}$ Moreover, Ti oxide layers formed on $\mathrm{Ti}$ subjected to multiple-stage cold rolling are less defective than in case of conventional, microcrystalline CP-Ti, as was confirmed by Mott-Schottky analysis. ${ }^{[33]}$

Nevertheless, oxide layer properties formed on Ti-based materials depend not only on the microstructure of the substrate but also on its chemical composition. It is known that valve alloying elements such as $\mathrm{Nb}$, Ta, and $\mathrm{Zr}$ can beneficially affect $\mathrm{Ti}$ corrosion resistance in body fluids by enhancing the stability of the oxide layers. ${ }^{[34-36]}$ However, available research works do not lend themselves to drawing general conclusions about the separate role of structural defects and the chemical composition of Ti-based substrate on the stability and, hence, protective properties of oxide layers. These difficulties derive from (i) the variety of techniques used to deform $\mathrm{Ti}$ and its alloys, causing different textures and grain size distribution, (ii) differences in the total cumulated strain during plastic deformation leading to different dislocation density, grain size and character of grain boundaries, and (iii) differences in the types of corrosion tests, corrosive solutions, immersion time and other given parameters.

Moreover, most corrosion studies related to novel Ti-based biomaterials, manufactured by large plastic deformation techniques, neglect the effect of the fluoride ions present in commercially available oral hygiene agents. Interaction between $\mathrm{F}^{-}$and $\mathrm{Ti}$ oxide leads to the formation of highly soluble Ti-F compounds ${ }^{[37]}$ and, hence, may result in the dissolution of $\mathrm{Ti}$ oxide layers. ${ }^{[38-40]}$ Difficulties with thorough cleaning of the fluoridated solution, which remain in the narrow crevices between implant/abutment and implant/tissue in the oral cavity, ${ }^{[4]}$ could be responsible for severe corrosion of Ti implants. Although the high number of structural defects provided by large plastic deformation can accelerate the passivation process owing to their enhanced reactivity, they may also favor reactions between Ti-based substrate and $\mathrm{F}^{-}$ions. Moreover, the combined effect of structural defects and valve alloying elements on Ti corrosion in fluoridated medium has not been sufficiently studied. Therefore, it is difficult to assess what types of deformed material are more beneficial in terms of corrosion resistance in fluorides: commercially pure $\alpha$ Ti or its novel $\beta$-phased alloy.

Considering all of these limitations, the main aim of this study is to provide insight into the role of (i) valve alloying elements, (ii) high density of dislocations and grain boundaries, and (iii) a combination of both factors on the short- and long-term corrosion resistance of Ti-based materials in the simulated physiological solution enriched with fluoride ions. In order to assess the separate influence of the following factors, an investigation was performed on the CP-Ti and TNTZ alloy in microcrystalline state and after multiple-stage cold rolling, which can be scaled up to the industrial level. In addition, an analysis of mechanical properties was performed, owing to its importance in long-lasting biomedical applications of fabricated materials.

\section{EXPERIMENTAL}

\section{A. Materials Fabrication and Microstructural Characterization}

In this work, the following materials were tested: CP-Ti (Ti Grade 2- $\alpha$ phased) and $\mathrm{Ti}-29 \mathrm{Nb}-$ $13 \mathrm{Ta}-4.6 \mathrm{Zr}$ alloy in the solution-treated state (TNTZmetastable $\beta$ phased). Materials were sourced from two companies: WOLFTEN supplied Ti Grade 2 in the annealed state while TNTZ was produced by TIMET UK company. Pure elements necessary to produce TNTZ alloy were supplied by ALFA AESAR in the form of pellets. As-casted TNTZ alloy was subjected to the series of plastic deformation treatments (such as hot rolling) which were optimized by TIMET UK company. Then, in order to obtain microstructure composed of equiaxed grains of $\beta$ phase, TNTZ alloy was heat treated at $950{ }^{\circ} \mathrm{C}$ for 30 minutes. In order to avoid the oxidation during heat treatment, TNTZ alloy was placed in a glass capsule filled with argon. Immediately after heat treatment, glass capsule with TNTZ bar was placed and broken in the water. For the purposes of assessing whether a high number of structural defects would optimize corrosion and mechanical performance, $\mathrm{Ti}$ Grade 2 and TNTZ were processed by multiple-pass cold rolling with a total reduction ratio of $90 \mathrm{pct}$, which corresponds to an equivalent strain $\varepsilon_{\mathrm{CR}}=2.66$. In case of both materials, the initial products subjected to the cold-rolling procedure had the following dimensions: 10 $\times 10 \times 50 \mathrm{~mm}$. The final products had the $1 \mathrm{~mm}$ of thickness.

The microstructure of the microcrystalline samples (micro-Ti and micro-TNTZ) was revealed by Kroll's Etchant (sourced from Chempur) and characterized by a Nikon EPIHOT 200 optical microscope. For microcrystalline materials, grain sizes were provided by calculation of equivalent grain diameters $E\left(\mathrm{~d}_{2}\right)$ using Micrometer program. ${ }^{[2]}$ This parameter can be described as a diameter of a circle which surface area is the same as the surface area of particular grain. A TEM JEOL 1200 transmission electron microscope was used to evaluate the microstructure in cold-rolled samples (CR Ti and CR TNTZ). Samples for TEM observations were prepared by using Electrolyte A3 Struers to electropolish $0.1 \mathrm{~mm}$ thick and $3 \mathrm{~mm}$ diameter plates. Selected parameters of electropolishing were as follows (CR Ti: $37 \mathrm{~V} / 2{ }^{\circ} \mathrm{C}$, CR TNTZ: $35 \mathrm{~V} /-$ $35^{\circ} \mathrm{C}$ ). For TNTZ alloy, additional EBSD microtexture analysis was performed using SEM HITACHI SU-70 scanning electron microscope with an acceleration voltage of $20 \mathrm{kV}$. For all of tested samples, microscopic characterization was supplemented by X-ray diffraction (XRD) analysis using Bruker D8 Advance diffractometer (with $\mathrm{Cu} \mathrm{K} \alpha$ radiation source: $K_{\alpha 1}=1.54056 \AA$ ). XRD studies enabled to analyze phase structure and to designate the lattice parameters of tested materials. Lattice parameters were calculated based on the following formulas: 
hep lattice (micro-Ti and CR Ti): $\frac{1}{d_{h k l}^{2}}=\frac{4}{3}\left(\frac{h^{2}+h k+k^{2}}{a^{2}}\right)+\frac{l^{2}}{c^{2}}$,

bcc lattice (micro-TNTZ and CR TNTZ): $a_{h k l}=\frac{\lambda \sqrt{h^{2}+k^{2}+l^{2}}}{2 \sin \theta}$,

where $a$ and $c$ mean the lattice parameters $(\AA),(h k l)$ means Miller index for particular diffraction peaks from $\alpha$ or $\beta$ phases, $d_{h k l}$ means the interplanar distance $(\AA)$, and $\theta$ means the diffraction angle for particular XRD peaks.

\section{B. Mechanical Properties}

Long-term implantation success is governed by the material's functional properties such as corrosion resistance as well as by its mechanical performance, especially mechanical strength and elastic modulus. Mechanical properties were characterized by means of uniaxial tensile tests performed on miniaturized samples, as presented in Figure 1 (described in detail in References 43 and 44). Test specimens were cut by electrical discharge machining (EDM) along the rolling direction. Uniaxial tensile tests were performed at an initial strain rate of $10^{-3} \mathrm{~s}^{-1}$ using a Zwick/Roell Z005 static testing machine equipped with a $5 \mathrm{kN}$ load cell. Each analyzed state was represented by two specimens. Digital image correlation (DIC) was used to measure strain with respect to the procedure presented in Reference 45 . Based on the stress-strain curves obtained, Young's modulus $(E), 0.2$ pct offset yield strength (YS), ultimate tensile strength (UTS), uniform elongation $\left(A_{\mathrm{u}}\right)$, and total elongation to failure $(A)$ were estimated according to the ISO 6892-1 standard.

\section{Surface Characterization}

Changes in microstructure induced by large plastic deformation can affect the morphology as well as chemical composition of the Ti surface with respect to the fraction of particular oxides. Morphology of the Ti and TNTZ alloy surface was characterized by Carl Zeiss Axio Scope optical microscope (with a differential interference contrast-DIC). Surface chemical

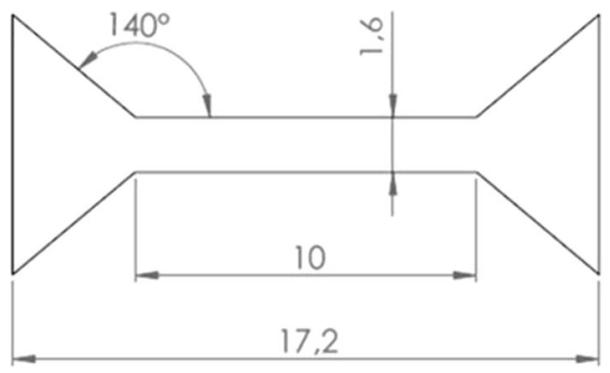

Thickness $1.0 \mathrm{~mm}$

Fig. 1-Miniaturized sample used for uniaxial tensile tests. composition was characterized by an XPS Microlab 350 (Thermo Elektron) X-ray photoelectron spectroscope using $\mathrm{A} 1 \mathrm{~K} \alpha$ non-monochromated radiation ( $h v=$ $1486.6 \mathrm{eV}$ ) as the exciting source. The binding energy of the target elements ( $\mathrm{Ti} 2 \mathrm{p}, \mathrm{O} 1 \mathrm{~s}, \mathrm{C} 1 \mathrm{~s}, \mathrm{~N} \mathrm{1s}$, etc.) was determined at a pass energy of $40 \mathrm{eV}$, using the binding energy of carbon as a reference $(\mathrm{C} 1 \mathrm{~s}: 285 \mathrm{eV})$. The chemical states of the components were characterized over a representative $2 \times 5 \mathrm{~mm}$ surface area, and appropriate standards for the XPS reference spectra were also used. Smart background subtraction was applied to obtain XPS signal intensity. The peaks were fitted using an asymmetric Gaussian/Lorentzian mixed function. XPS analysis was performed on the polished surfaces and was repeated after their 168 hours of immersion in the artificial saliva enriched with fluorides. For TNTZ alloy, the surface characterization was supplemented by EDS analysis which allowed to evaluate the homogeneity of alloying elements distribution. EDS linear analysis was performed using a SEM HITACHI SU-70.

\section{Corrosion Response}

Surface properties of Ti-based materials were characterized by electrochemical techniques. Samples for the corrosion studies were ground up to \#4000 and polished to a mirror-like finish using OP-S Struers $0.04 \mu \mathrm{m}$ silica suspension. Since electrochemical parameters can be affected by surface roughness, the repeatability of the polishing procedure for all samples was verified by a Carl Zeiss Axio Scope optical microscope. Surface area subjected to electrochemical tests was limited by Teflon element with O-ring (inner diameter-3.5 mm). Therefore, for all of the samples, surface area subjected to the electrochemical tests was the same-c.a. $10 \mathrm{~mm}^{2}(0.1$ $\mathrm{cm}^{2}$ ). All of the corrosion measurements were carried out in artificial saliva (Fusayama recipe ${ }^{[46]}$ ) with 1500 ppm $\mathrm{F}^{-}(0.15 \mathrm{pct})$ in order to simulate the effect of using commercially available toothpastes. ${ }^{[4]}$ Electrochemical tests were performed using a three-electrode setup (working electrode-Ti/TNTZ sample, reference electrode- $\mathrm{Ag} / \mathrm{AgCl}$ saturated electrode, counter electrode-platinum) combined with Autolab PGSTAT $302 \mathrm{~N}$ potentiostat/galvanostat. The electrochemical tests included the following stages: open-circuit potential (OCP) monitoring for 20 hours after immersion, electrochemical impedance spectroscopy (EIS) tests performed 20 and 168 hours (7 days) after immersion, and potentiodynamic polarization (PD) performed immediately after EIS - 170 hours after immersion. EIS tests were performed in the frequency range $1 \mathrm{kHz}$ to $1 \mathrm{mHz}$ at OCP (amplitude $10 \mathrm{mV}$ ). PD measurements were conducted in the potential range $-0.2 \mathrm{~V}+\mathrm{OCP}$ to $2.0 \mathrm{~V}+\mathrm{OCP}$ with a scan rate of $1 \mathrm{mV} / \mathrm{s}$. Measurements and fitting procedures were performed using NOVA 2.1.4 software (Metrohm Autolab). All of the electrochemical measurements were replicated, and the medium values of parameters were analyzed. Electrochemical tests gave the possibility for a qualitative description and comparison of the protective properties of oxide layers formed on the tested samples. 


\section{RESULTS AND DISCUSSION}

\section{A. Microstructural Characterization}

Light microscopy (LM) observations revealed that the microstructure of the initial Ti-based materials is composed of equiaxed grains with the mean diameter $33 \pm$ $15 \mu \mathrm{m}$ (Figure 2(a)) and $97 \pm 41 \mu \mathrm{m}$ (Figure 2(b)) for Ti and TNTZ, respectively. The multiple-pass cold rolling resulted in substantial rebuilding of the microstructure (Figures 2(c) and (d)). The fractions of the bands with the width $<100 \mathrm{~nm}$ as well as $>200 \mathrm{~nm}$, elongated in the rolling direction, with the high density of dislocations in their interior can be clearly distinguished in TEM micrographs of CR TNTZ (Figure 2(d)). In case of CR Ti (Figure 2(c)), bands were less visible which is associated with more developed stage of microstructure evolution compared to CR TNTZ. ${ }^{[48]}$ For CR Ti, the cellular structures and non-numerous nanometric subgrains (size 100 to $200 \mathrm{~nm}$ ) were visible, which were formatted through fragmentation of dislocation bands at the advanced stage of deformation. For CR TNTZ only single, separate subgrains can be distinguished (Figure 2(d)). Observed differences can be associated with differential crystallography of the materials (hcp system-Ti and bcc system-TNTZ) which resulting in the discrepancies between their microstructure evolutions during plastic deformation. ${ }^{[49,50]}$ The less advanced process of grain refinement for $\mathrm{Ti} \beta$-phased alloy compared to $\mathrm{CP}-\mathrm{Ti}$ was also confirmed for materials deformed by hydrostatic extrusion (HE) ${ }^{[51]}$

XRD analysis revealed peaks broadening after cold-rolling procedure which can be associated with the formation of the nanometric subgrains (Figure 3). ${ }^{[52]}$ In addition, in case of TNTZ alloy cold-rolling process led to intensification of $\alpha^{\prime \prime}$ peaks, especially (200) $\alpha^{\prime \prime}$, which can be associated with the stress-induced martensitic transformation (Figure 3). ${ }^{[53]}$ However, subjecting TNTZ to cold rolling provided virtually no changes in the dimension of the unit cell (Table I). This is in agreement with the results reported previously for other cold-rolled TNTZ alloy (Ti-29Nb-9Ta-10Zr). ${ }^{[54]}$ For pure $\mathrm{Ti}$, a decrease of $c$ parameter from 4.689 to 4.679 after cold-rolling process was detected, whereas no significant changes were observed in case of $a$ parameter value (Table I).

\section{B. Mechanical Properties}

The representative stress-strain curves obtained for $\mathrm{Ti}$ and TNTZ are presented in Figure 4, whereas the estimated mechanical properties are summarized in Table II. The micro-Ti exhibited the following mechanical parameters: $E=107.8 \pm 4.1 \mathrm{GPa}, \mathrm{YS}=321 \pm 1$ $\mathrm{MPa}$, UTS $=434 \pm 1 \mathrm{MPa}$ which are typical values for annealed commercially pure $\mathrm{Ti}^{[55]}$ As was previously reported, ${ }^{[56]}$ the microcrystalline TNTZ had a
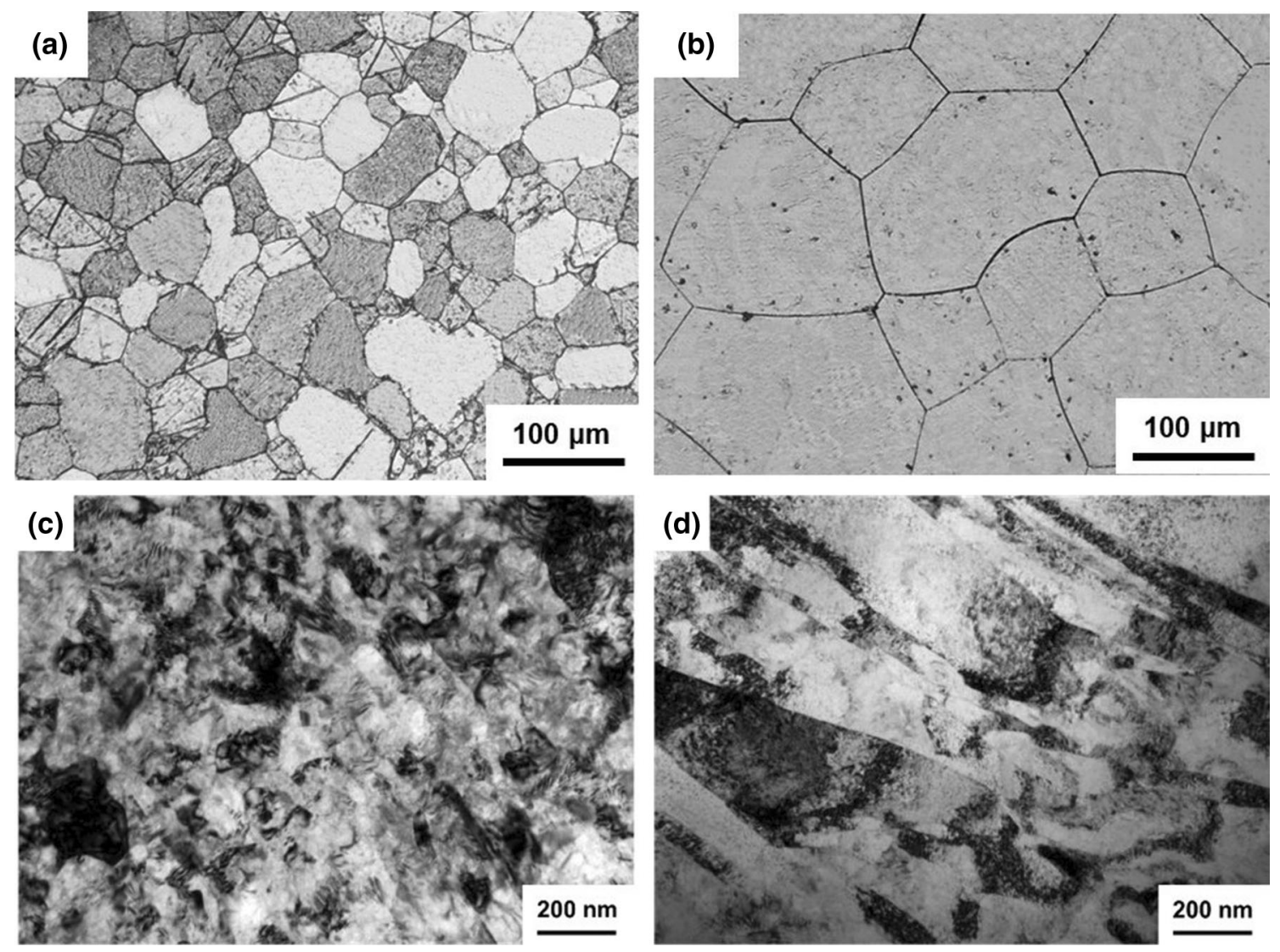

Fig. 2-Microstructure of the tested Ti-based materials $(a)$ micro-Ti, $(b)$ micro-TNTZ, $(c)$ CR Ti, and $(d)$ CR TNTZ. 

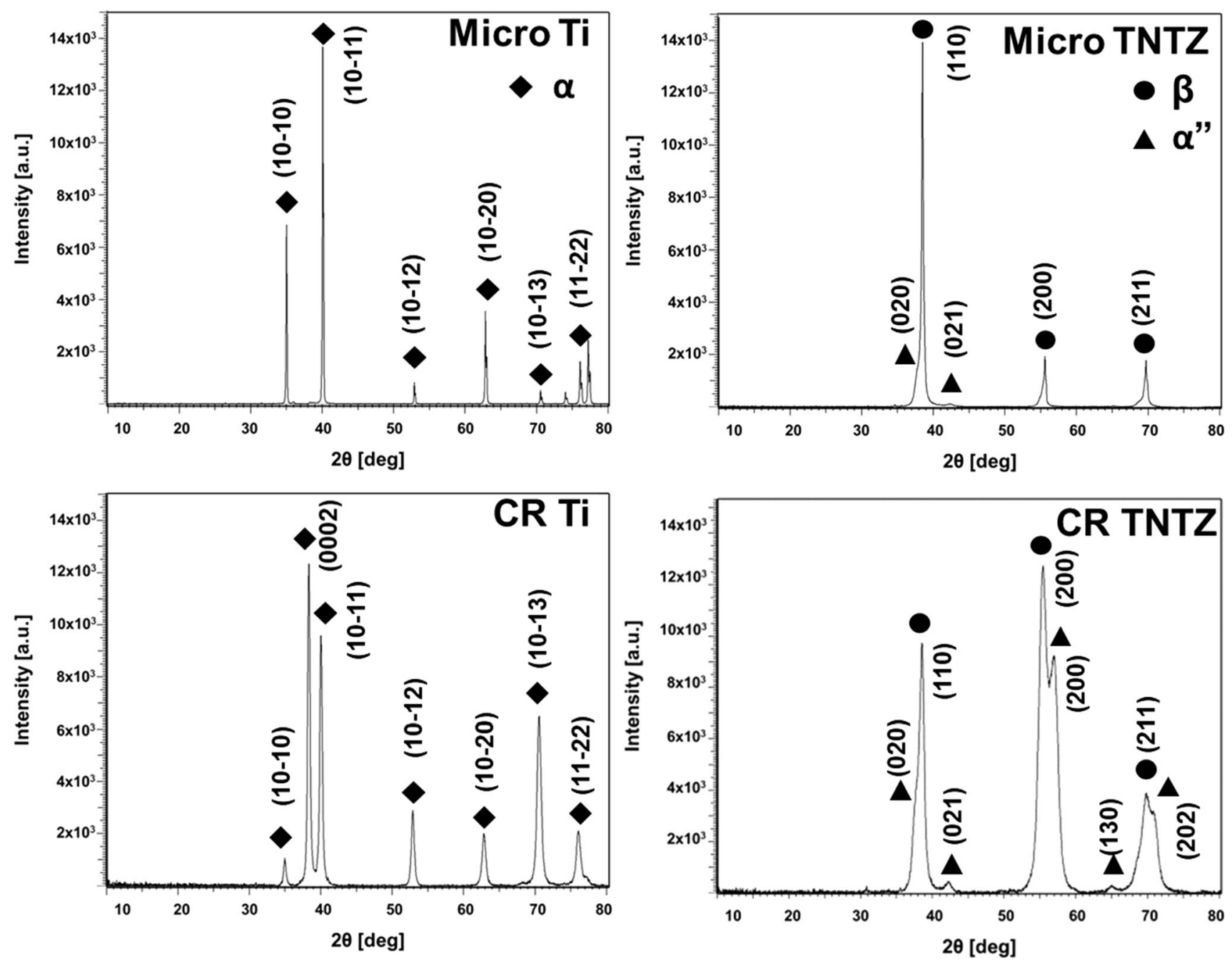

Fig. 3-XRD patterns of Ti and TNTZ alloy before and after cold-rolling process.

Table I. Lattice Parameters of Ti and TNTZ Before and After Cold-Rolling Process

\begin{tabular}{llll}
\hline & \multicolumn{2}{c}{$\alpha$ Phase } & $\beta$ Phase \\
Sample State & $a(\AA)$ & $c(\AA)$ & $a(\AA)$ \\
\hline Micro-Ti & 2.952 & 4.689 & - \\
CR Ti & 2.955 & 4.679 & - \\
Micro-TNTZ & - & - & 3.300 \\
CR TNTZ & - & - & 3.301 \\
\hline
\end{tabular}

significantly lower Young's modulus of $62.0 \pm 0.2 \mathrm{GPa}$ but a similar YS of $306 \pm 4 \mathrm{MPa}$ and UTS of $505 \pm 4$ $\mathrm{MPa}$. The "double yielding" phenomenon with a flat plateau on the stress-strain curve was noticed for microcrystalline TNTZ as well. It corresponded to the stress-induced martensitic transformation occurring during tensile deformation, which is typically observed for metastable $\beta$ phase titanium alloys for the stress range 190 to $360 \mathrm{MPa}^{[57]}$ The cold-rolled samples exhibited higher YS $(679 \pm 17$ and $446 \pm 3 \mathrm{MPa}$ for Ti

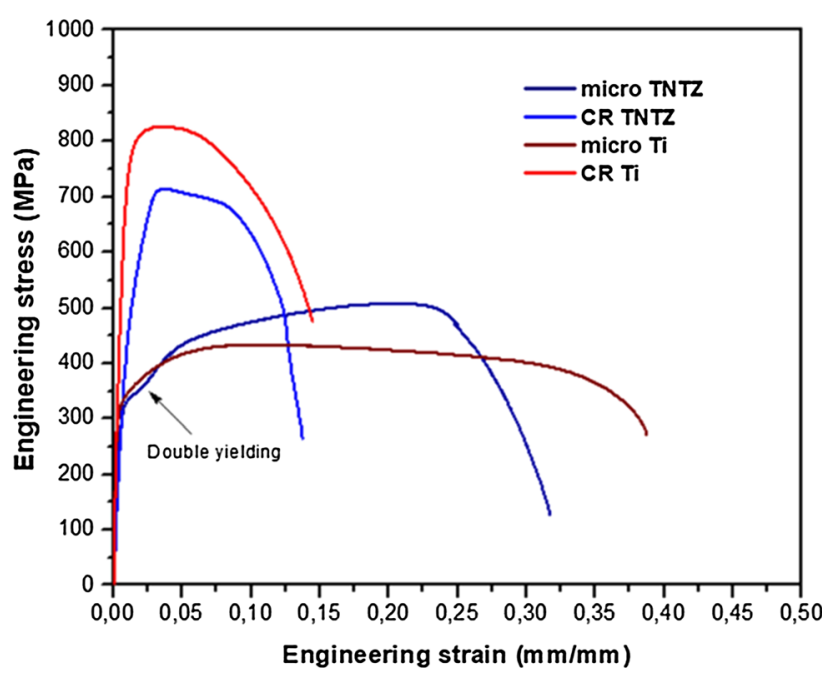

Fig. 4-Representative stress-strain curves of microcrystalline and CR Ti and TNTZ.

and TNTZ, respectively) and UTS (840 \pm 13 and $713 \pm$ $1 \mathrm{MPa}$ for $\mathrm{Ti}$ and $\mathrm{TNTZ}$, respectively) which were 
Table II. Mechanical Properties ( $E$ Young's Modulus, YS Yield Strength, UTS Ultimate Tensile Strength, $A_{\mathrm{u}}$ Uniform Elongation, $A$ Elongation to Failure) of Ti and TNTZ

\begin{tabular}{|c|c|c|c|c|c|}
\hline Sample & $E(\mathrm{GPa})$ & YS (MPa) & UTS (MPa) & $A_{\mathrm{u}}(\mathrm{Pct})$ & $A(\mathrm{Pct})$ \\
\hline Micro-Ti & $107.8 \pm 4.1$ & $321 \pm 1$ & $434 \pm 1$ & $10.1 \pm 0.2$ & $37.3 \pm 1.2$ \\
\hline CR Ti & $106.8 \pm 3.3$ & $679 \pm 17$ & $840 \pm 13$ & $2.8 \pm 0.1$ & $14.3 \pm 0.3$ \\
\hline Micro-TNTZ & $62.0 \pm 0.2$ & $306 \pm 4$ & $505 \pm 4$ & $20.1 \pm 0.1$ & $31.4 \pm 0.1$ \\
\hline CR TNTZ & $52.3 \pm 0.4$ & $446 \pm 3$ & $713 \pm 1$ & $2.2 \pm 0.1$ & $12.9 \pm 0.3$ \\
\hline
\end{tabular}
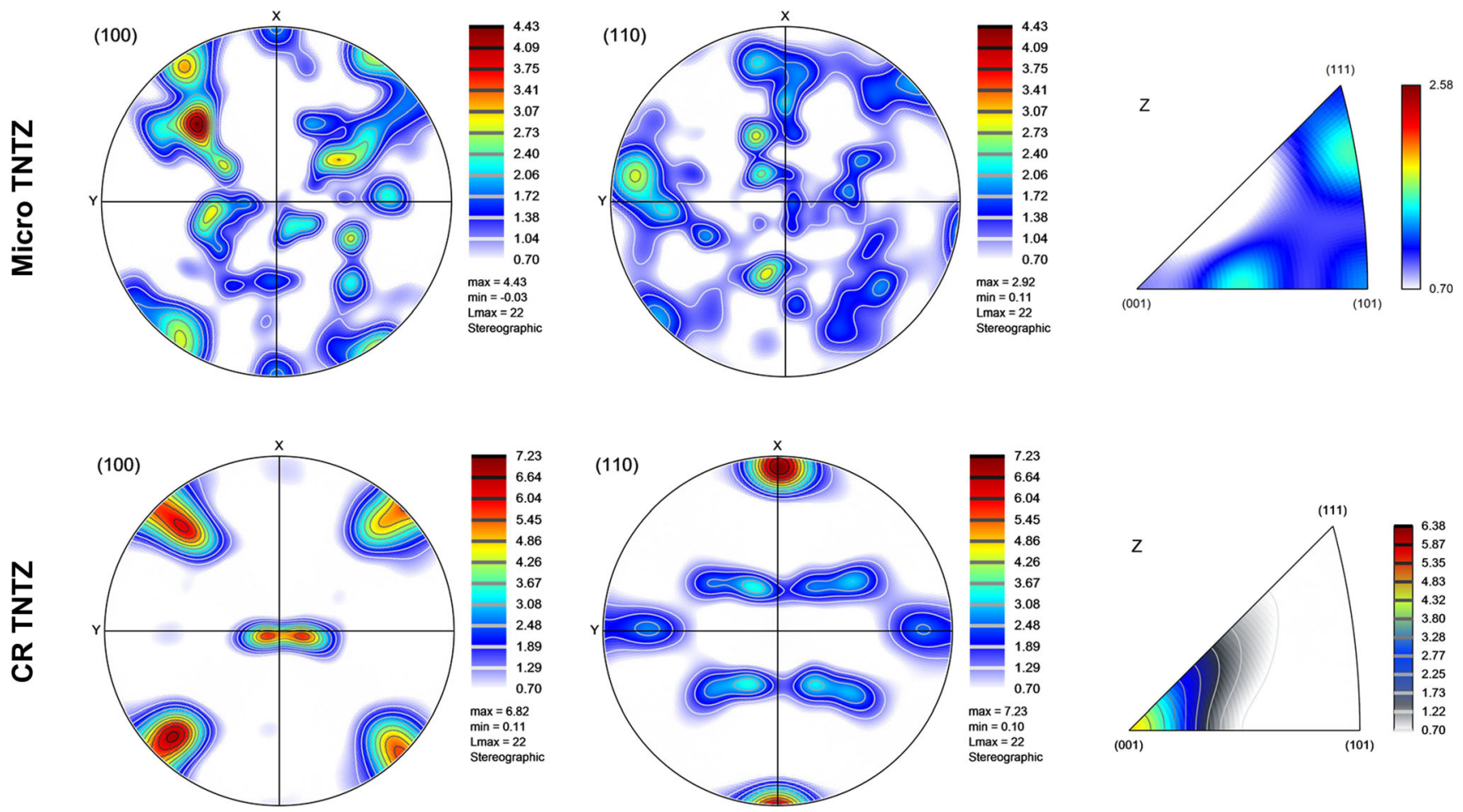

Fig. 5-EBSD microtexture analysis of micro- and CR TNTZ alloy.

superior to those observed for their microcrystalline counterparts. On the other hand, the strength enhancement caused a deterioration of elongation to failure to $14.3 \pm 0.3$ and $12.9 \pm 0.3$ pct for CR Ti and CR TNTZ, respectively. Despite having the same processing parameters, the strength of CR Ti increased to a far greater degree than it did for CR TNTZ. This can derive from differences in the microstructural evolution of $\alpha$ Ti and $\beta$-phased $\mathrm{Ti}$ alloys during unidirectional cold rolling which is associated with differential lattice structure and stacking fault energy. ${ }^{[58]}$ In case of bcc metals $\langle 111\rangle$, close-packed directions, along which dislocation slip is the most likely, belong to many slip planes. This may lower the rate of dislocation intersections and establishing new boundaries due to possibility of the cross slip. In hop lattice, there is only one slip plane with many directions which favor dislocation jogs and grain refinement. ${ }^{[58]}$ This can be the reason why the high fraction of cellular structures divided by the transverse dislocation boundaries is visible for CR Ti (Figure 2(c)). The high fraction of transverse dislocation boundaries, which acts as obstacles for dislocation motion, could explain the greater UTS value for CR Ti than for CR TNTZ. It is worth noting that the cold-rolling process significantly lowered the Young's modulus of CR TNTZ. The decrease in stiffness can be related to the strengthening of $\{001\}\langle 110\rangle$ texture component associated with the $\alpha$-fiber texture (Figure 5), frequently observed in case of cold-rolled $\beta$-phased metals. Development of this type of texture was indicated as the possible reason of the elastic modulus reduction observed for another $\mathrm{Ti}$ $\beta$-phased alloys ( $\mathrm{Ti}-\mathrm{Nb}-\mathrm{Mo}-\mathrm{Zr}^{[59]}$ and $\mathrm{Ti}-\mathrm{Nb}-\mathrm{Zr}-$ $\mathrm{Sn}^{[60]}$ ) after cold-rolling process. As shown by Tane et al., ${ }^{[61]}$ the Young's modulus of Ti-Nb-Ta-Zr alloys is highly affected by the crystallographic orientation. It reaches for $\mathrm{Ti}-29 \mathrm{Nb}-13 \mathrm{Ta}-4.6 \mathrm{Zr}$ alloy the lowest value of about $35 \mathrm{GPa}$ in the $\langle 100\rangle$ direction while it is even two times higher in the $\langle 111\rangle$ direction $(\sim 80 \mathrm{GPa})$. The intermediate value of about $60 \mathrm{GPa}$ is achieved in the $\langle 110\rangle$ direction which dominates in the investigated CR TNTZ during tensile along rolling direction. Moreover, reduction of elastic modulus value in case of cold-rolled Ti $\beta$ alloys could be associated also to the development of stress-induced martensite: (200) $\alpha^{\prime \prime},{ }^{[53,62]}$ which was 

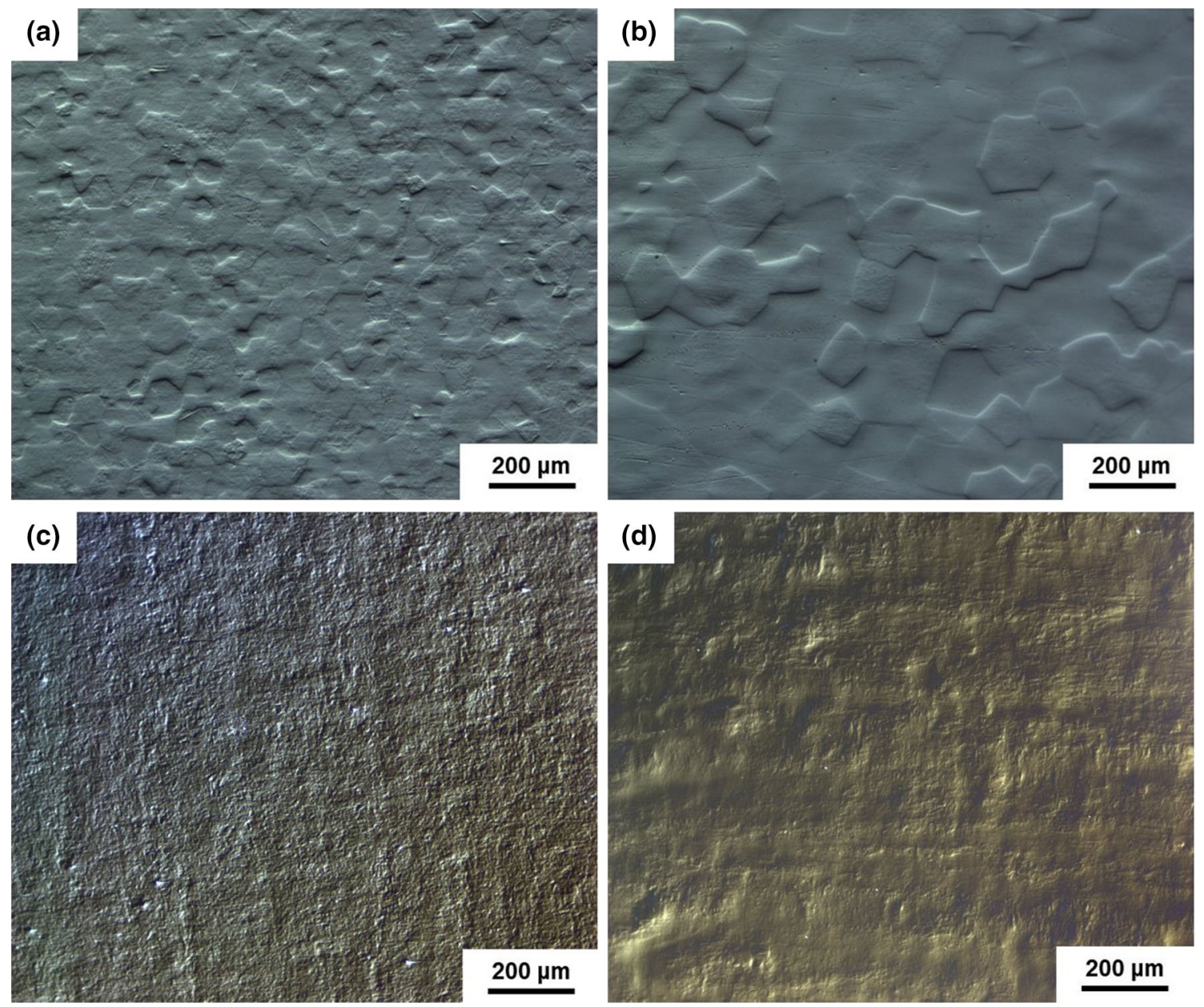

Fig. 6-Mirror-like polished surfaces prepared for XPS and corrosion tests observed by optical microscope with differential interference contrast (DIC) (a) micro-Ti, (b) micro-TNTZ, (c) CR Ti, and (d) CR TNTZ.

detected during XRD analysis (Figure 3). Thereby, we claim that the decrease of TNTZ elastic modulus reported in this study is related to the combined effect of texture evolution and increased volume fraction of stress-induced martensite $\alpha^{\prime \prime}$. With pure Ti, changes in stiffness were not observed after multiple-pass cold rolling. Although the elastic modulus value is governed mainly by the chemical and phase composition, introducing a large number of structural defects can also influence stiffness. Deformation-induced reduction of stiffness (c.a. 13 pct) was observed for Ti subjected to HE with clearly formatted nanosized grains. ${ }^{[63]}$ Hence, it can be assumed that in the case of $\alpha$-phased $\mathrm{Ti}$, this effect is associated with the large number of welldefined high-angle grain boundaries (HAGB), which were not observed in the CR Ti investigated in this study.

Summing up, the process of multiple-pass cold rolling substantially increases the mechanical strength of $\mathrm{Ti}$ Grade 2 and TNTZ alloy. The UTS value for cold-rolled materials was close to Ti6Al4V alloy, commonly used for load-bearing applications. ${ }^{[11]}$ Moreover, large plastic deformation results in the reduction of TNTZ stiffness $(E=52.3 \pm 0.4 \mathrm{GPa})$ which is getting closer to the
Young's modulus of bone (10 to $30 \mathrm{GPa}) .{ }^{[7]}$ Enhanced mechanical strength combined with low stiffness is an essential factor in terms of highly loaded implants, such as miniaturized dental replacements which are in contact with bone tissue.

\section{Surface Characterization}

Substantial changes in the microstructure induced by large plastic deformation can also be responsible for differences in surface morphology and chemical composition. Although surfaces were polished to a mirror finish with a silica suspension (widely used in the preparation of Ti biomedical materials), LM observations with DIC mode revealed differences in surface topography (Figure 6). This effect is associated with large plastic deformation introducing a huge number of structural defects, which acts as privileged sites for oxide layer formation. Deformation-induced differences in surface nano-topography were observed and described quantitatively for commercially pure $\mathrm{Ti}$ subjected to ECAP. ${ }^{[64]}$ The surfaces of the polished samples (Figure 6) were subsequently characterized in terms of their chemical composition by XPS. 
Table III. Chemical Composition of the Oxide Layers Formed on the Ti Grade 2 Surface (Mirror-Like Polished Surface)

\begin{tabular}{|c|c|c|c|c|c|}
\hline & Peak & BE Peak & Chemical State & Pct in Oxide Layer & At. Pct \\
\hline \multirow[t]{5}{*}{ Micro-Ti } & Ti2p3 & 458.8 & $\mathrm{TiO}_{2}$ & 67.4 & Ti 23.7 \\
\hline & & 453.9 & Ti metal & 12.9 & O 48.4 \\
\hline & & 456.2 & $\mathrm{TiO}$ & 11.7 & C 25.5 \\
\hline & & 457.5 & $\mathrm{Ti}_{2} \mathrm{O}_{3}$ & 8.0 & N 1.2 \\
\hline & & & & & Si 1.2 \\
\hline \multirow[t]{5}{*}{ CR Ti } & Ti2p3 & 458.8 & $\mathrm{TiO}_{2}$ & 74.9 & Ti 22.9 \\
\hline & & 453.7 & Ti metal & 10.1 & O 48.1 \\
\hline & & 455.2 & $\mathrm{TiO}$ & 6.7 & C 26.2 \\
\hline & & 456.8 & $\mathrm{Ti}_{2} \mathrm{O}_{3}$ & 8.3 & N 0.9 \\
\hline & & & & & Si 1.9 \\
\hline
\end{tabular}

Table IV. Chemical Composition of the Oxide Layers Formed on TNTZ Surface (Mirror-Like Polished Surface)

\begin{tabular}{|c|c|c|c|c|c|}
\hline & Peak & BE Peak & Chemical State & Pct in Passive Layer & At. Pct \\
\hline \multirow[t]{11}{*}{ Micro-TNTZ } & \multirow[t]{4}{*}{ Ti2p3 } & 458.7 & $\mathrm{TiO}_{2}$ & 41.2 & Ti 16.4 \\
\hline & & 453.5 & Ti metal & 5.9 & $\mathrm{Nb} 7.7$ \\
\hline & & 455.6 & $\mathrm{TiO}$ & 7.0 & Ta 2.3 \\
\hline & & 457.3 & $\mathrm{Ti}_{2} \mathrm{O}_{3}$ & 7.0 & Zr 0.5 \\
\hline & \multirow[t]{2}{*}{$\mathrm{Nb} 3 \mathrm{~d} 5$} & 207.1 & $\mathrm{Nb}_{2} \mathrm{O}_{5}$ & 23.2 & O 49.5 \\
\hline & & 201.8 & $\mathrm{Nb}$ metal & 5.6 & C 20.9 \\
\hline & \multirow[t]{2}{*}{ Zr3d5 } & 182.2 & $\mathrm{ZrO}_{2}$ & 1.5 & Si 2.7 \\
\hline & & 177.9 & $\mathrm{Zr}$ metal & 0.3 & \\
\hline & \multirow[t]{3}{*}{ Ta4f7 } & 25.5 & $\mathrm{Ta}_{2} \mathrm{O}_{5}$ & 3.1 & \\
\hline & & 20.9 & Ta metal & 4.0 & \\
\hline & & 24.6 & $\mathrm{TaO}_{2}$ & 1.3 & \\
\hline \multirow[t]{11}{*}{ CR TNTZ } & \multirow[t]{4}{*}{ Ti2p3 } & 458.8 & $\mathrm{TiO}_{2}$ & 40.5 & Ti 14.8 \\
\hline & & 453.6 & Ti metal & 7.4 & $\mathrm{Nb} 7.0$ \\
\hline & & 456.0 & $\mathrm{TiO}$ & 7.1 & Ta 1.8 \\
\hline & & 457.4 & $\mathrm{Ti}_{2} \mathrm{O}_{3}$ & 6.7 & Zr 0.3 \\
\hline & \multirow[t]{2}{*}{$\mathrm{Nb} 3 \mathrm{~d} 5$} & 207.1 & $\mathrm{Nb}_{2} \mathrm{O}_{5}$ & 22.8 & O 45.7 \\
\hline & & 201.8 & $\mathrm{Nb}$ metal & 6.6 & C 24.7 \\
\hline & \multirow[t]{2}{*}{ Zr3d5 } & 182.2 & $\mathrm{ZrO}_{2}$ & 1.2 & Si 5.8 \\
\hline & & 178.0 & $\mathrm{Zr}$ metal & 0.2 & \\
\hline & \multirow[t]{3}{*}{ Ta4f7 } & 25.5 & $\mathrm{Ta}_{2} \mathrm{O}_{5}$ & 3.7 & \\
\hline & & 20.8 & Ta metal & 2.8 & \\
\hline & & 24.2 & $\mathrm{TaO}_{2}$ & 1.1 & \\
\hline
\end{tabular}

XPS analysis performed for Ti samples revealed that multiple-pass cold rolling led to the formation of a more stoichiometric oxide layer on Ti surface, as was demonstrated by the higher fraction of $\mathrm{TiO}_{2}$ in the case of CR $\mathrm{Ti}$ (Table III). An increased fraction of $\mathrm{TiO}_{2}$ induced by large plastic deformation was also observed for $\mathrm{Ti}$ Grade $2^{[65]}$ and Ti Grade $4^{[64]}$ subjected to ECAP and was associated with better corrosion properties in chloride-rich solutions. ${ }^{[65]}$ Detection of metallic $\mathrm{Ti}$ indicates that the air-formed oxide layer demonstrates nanometric thickness, as was confirmed by AES measurements in our previous study ${ }^{\left[{ }^{[6]}\right.}$ Moreover, assuming that the oxidation state of Ti changes gradually from $\mathrm{Ti}(\mathrm{IV})$ to metallic $\mathrm{Ti},{ }^{[30,64]}$ the air-formed passive layer is believed to be slightly thicker for $\mathrm{CR} \mathrm{Ti}$ than for micro-Ti. The greater thickness of the oxide layer was claimed to be the reason for the higher $\mathrm{Ti}$ corrosion resistance after other large deformation processes. ${ }^{[33,67]}$
As with pure $\mathrm{Ti}, \mathrm{TiO}_{2}$ is the main component of the passive layer formed on the TNTZ surface. Oxides of alloying elements $\left(\mathrm{Nb}_{2} \mathrm{O}_{5}, \mathrm{Ta}_{2} \mathrm{O}_{5}\right.$, and $\left.\mathrm{ZrO}_{2}\right)$ were also found and the lower oxidation states of $\mathrm{Nb}$, Ta, and $\mathrm{Zr}$ were detected in significantly smaller amounts (Table IV). In contrast to Ti, no significant differences were observed in the fraction of particular oxides for TNTZ after the cold-rolling process. This suggests that the oxides of alloying elements stabilize the $\mathrm{TiO}_{2}$ passive layer, resulting in it being less susceptible to rebuilding due to the introduction of a great density of structural defects. Moreover, a similar fraction of the metallic form of particular alloying elements suggests that there is virtually no difference between the thickness of the passive layer formed on micro- and CR TNTZ.

XPS analysis was repeated after 168 hours of samples immersion in the fluoridated artificial saliva (Tables V, VI). Detection of additional F 1 s peak at the binding 
energy around $685 \mathrm{eV}$ indicates the presence of hexafluorotitanate complex compound $\left(\mathrm{Na}_{2} \mathrm{TiF}_{6}\right)$ which is formed owing to the interactions between titanium oxide layer and fluorides. ${ }^{[41,68]}$ For pure Ti (micro-Ti and CR Ti), the amount of this complex in the surface was around 1 pet while for TNTZ alloy (micro- and CR TNTZ) around 0.5 pct. Another changes induced by materials immersion are associated with the percentage amount of $\mathrm{Ti}$ and alloying elements on particular oxidation states. For micro-Ti, it was found that 168 hours of immersion in fluoridated saliva led to increase the amount of $\mathrm{TiO}_{2}$ with simultaneous decrease of metallic Ti (Tables III, V). This can be associated with the passive layer thickening in the solution. In contrast, for CR Ti virtually, no change in the amount of metallic Ti was observed after its immersion in fluoridated saliva. This indicates that the passive layer formed on CR Ti is stable in the solution. In case of TNTZ alloy, 168 hours of immersion resulted in the increase amount of $\mathrm{Nb}_{2} \mathrm{O}_{5}$ and $\mathrm{Ta}_{2} \mathrm{O}_{5}$ oxides (Table VI). This is in agreement with the results obtained for binary $\mathrm{Ti}-\mathrm{Nb}$ alloy for which a decline of $\mathrm{Ti}$ to $\mathrm{Nb}$ ratio was observed after immersion in artificial saliva (with and without fluorides). ${ }^{[6]}$ For TNTZ alloy (in both microcrystalline and cold-rolled states), analysis of surface chemical composition by XPS was supplemented by EDS evaluation (Figure 7). Performing this experiments was necessary to establish the distribution of alloying elements which can influenced corrosion behavior. EDS analysis revealed that in case of both analyzed TNTZ materials, distribution of alloying elements was rather homogenous (Figure 7).

\section{Corrosion Response}

Corrosion response of $\mathrm{Ti}$ and $\mathrm{TNTZ}$ alloy was evaluated on the basis of the results of OCP monitoring for 20 hours, EIS tests performed twice: after 20 and 168 hours of immersion in fluoridated saliva and PD measurements performed after the second EIS tests (170 hours after immersion in the solution). For micro-Ti, the OCP value increased by c.a. $0.2 \mathrm{~V}$ while for CR Ti by c.a. $0.15 \mathrm{~V}$ during immersion in fluoridated saliva (Figure 8). It can be associated with the progressive build-up of $\mathrm{Ti}$ oxides layers in the solution. Regardless the microstructure, for TNTZ alloy, virtually no changes in OCP were observed (OCP value increased for about $0.05 \mathrm{~V}$ after 20 hours of immersion).

For all of tested materials, a single maximum was detected on the phase angle part of Bode spectra (Figures 9(a) and (b)), which suggests that the oxide layer formed on their surfaces is homogeneous in structure. For this reason, an electrical circuit with the single time constant $R_{\mathrm{s}}\left(R_{\mathrm{p}} Q_{\mathrm{p}}\right)$ was selected to analyze the EIS data (Figure $9(\mathrm{c})) . R_{\mathrm{s}}$ represents the resistance of the fluoridated solution while $R_{\mathrm{p}}$ represents the passive layer resistance. $Q_{\mathrm{p}}$ is the constant phase element (CPE) of which parameters ( $n$ and $Y_{\mathrm{p}}$ ) describe the degree of surface homogeneity and the ability to accumulate electrical charge on the Ti or TNTZ/solution interface. The electrical circuit selected in this study is commonly used to designate the EIS parameters for Ti-based materials in physiological solutions. ${ }^{[27,70]}$ For all of the fitting data, $\chi^{2}$ values were less than 0.05. Designated values of CPE parameter $\left(Y_{\mathrm{p}}\right)$ were in the range of $10^{-5}$ $\Omega^{-1} \mathrm{~cm}^{-2} \mathrm{~s}$, which is a typical for passive layers formed on $\mathrm{Ti}$ and its alloys tested in the biomedical solutions. ${ }^{[71,72]}$ According to the EIS spectra (Figure 9(a)) and $R_{\mathrm{p}}$ values (Figure $9(\mathrm{~d})$ ), microcrystalline TNTZ alloy demonstrated the best corrosion resistance 20 hours after immersion in fluoridated saliva. The $R_{\mathrm{p}}$ value designated for micro-TNTZ was approximately twice as high as those for micro-Ti. This underlines the beneficial effect of the valve alloying elements $(\mathrm{Nb}, \mathrm{Ta}$, $\mathrm{Zr}$ ) on the stability of $\mathrm{Ti}$ passive layers in the presence of fluorides. Superior corrosion resistance in fluoridated medium induced by the presence of valve alloying elements such as $\mathrm{Nb}$ and $\mathrm{Ta}$ was previously reported for binary ${ }^{[73]}$ as well as ternary ${ }^{[74]}$ Ti biomedical alloys. This could be associated with the higher valences of $\mathrm{Nb}$ and Ta compared to $\mathrm{Ti}$ and hence the ability to form oxides with higher oxidation states $\left(\mathrm{Nb}_{2} \mathrm{O}_{5}, \mathrm{Ta}_{2} \mathrm{O}_{5}\right)$. The presence of such oxides stabilizes the $\mathrm{Ti}$ passive layer by compensating for the lack of negative charge in the passive layer induced by the fraction of $\mathrm{Ti}^{3+}$ and $\mathrm{Ti}^{2+}$ ions in the oxide layer. ${ }^{[75-77]} \mathrm{Nb}_{2} \mathrm{O}_{5}$ and $\mathrm{Ta}_{2} \mathrm{O}_{5}$ were found to stabilize passive layers formed on Ti-based materials and reduce the tendency for local damage, which can be induced by the incorporation of $\mathrm{F}^{-}$ions through the passive layer. Similar observations were reported for $\mathrm{ZrO}_{2}$ oxides. Although $\mathrm{Zr}$ demonstrates the same valency as $\mathrm{Ti}, \mathrm{ZrO}_{2}$ is claimed to stabilize $\mathrm{Ti}$ oxide layers and enhance corrosion properties of Ti-based materials. ${ }^{[78,79]}$ Apart from virtually no differences in the surface chemical composition, subjecting TNTZ to multiple-pass cold rolling led to a lowering of its corrosion resistance evaluated 20 hours after immersion (Figures 9(a) and (d); Table VII). According to the literature, introducing structural defects to $\mathrm{Ti} \beta$ alloys enhances the stability of the oxide layers formed on their surface in non-aggressive solutions such as simulated body fluid (SBF). ${ }^{[80,81]}$ However, this observation was not confirmed in the presence of relatively high concentrations of fluoride ions, as can be found in commercially available toothpastes. ${ }^{[27]}$ In contrast to TNTZ alloy, subjecting pure Ti to cold-rolling process resulted in the enhancement of its corrosion resistance (Figures 9(a) and (d); Table VII). This can be associated with the higher fraction of stable $\mathrm{TiO}_{2}$ oxide within the air-formed passive layer on $\mathrm{CR} \mathrm{Ti}$ compared to micro-Ti (Table III). It can be concluded that both introducing valve alloying elements and high number of structural defects enhance the corrosion resistance of $\mathrm{Ti}$ after shorter immersion time (20 hours) in fluoridated medium. However, this beneficial effect is not synergistic.

For all of the samples, the fitting data revealed increased corrosion resistance after prolonged exposure to fluoridated medium, which is essential in terms of dental applications (Figure 9(d)). The EIS results show that this enhancement was most pronounced for CR Ti, which demonstrated the best long-term corrosion properties (Figures 9(b) and (d); Table VII). It was found that after 168 hours of immersion, CR Ti demonstrated the highest $R_{\mathrm{p}}$ value and the lowest value of $Y_{\mathrm{p}}$ which 
Table V. Chemical Composition of the Oxide Layers Formed on the Ti Surface (After $168 \mathrm{~h}$ of Immersion in Artificial Saliva +

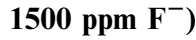

\begin{tabular}{|c|c|c|c|c|c|}
\hline & Peak & BE Peak & Chemical State & Pct in Surface & At. Pct \\
\hline \multirow[t]{7}{*}{ Micro-Ti } & \multirow[t]{4}{*}{ Ti2p3 } & 459.0 & $\mathrm{TiO}_{2}$ & 74.2 & Ti 21.3 \\
\hline & & 453.9 & Ti metal & 7.5 & O 43.5 \\
\hline & & 455.5 & $\mathrm{TiO}$ & 10.6 & C 29.7 \\
\hline & & 457.2 & $\mathrm{Ti}_{2} \mathrm{O}_{3}$ & 7.7 & $\mathrm{Ca} 0.6$ \\
\hline & \multirow[t]{3}{*}{ F 1s } & 687.4 & C-F (0.1) & - & N 0.7 \\
\hline & & 685.2 & F complex/fluorides $(0.7)$ & & F 0.9 \\
\hline & & 4500 & $\mathrm{TiO}_{2}$ & & $\begin{array}{l}\text { rest } 3.4 \\
\text { Ti } 23.4\end{array}$ \\
\hline \multirow{5}{*}{ CR Ti } & \multirow{3}{*}{ Ti2p3 } & $\begin{array}{l}459.0 \\
453.8\end{array}$ & $\begin{array}{l}1 U_{2} \\
\text { Ti metal }\end{array}$ & $\begin{array}{l}74.8 \\
9.0\end{array}$ & $\begin{array}{l}1123.4 \\
\text { O } 46.8\end{array}$ \\
\hline & & 455.5 & $\mathrm{TiO}$ & 9.4 & C 22.5 \\
\hline & & 457.1 & $\mathrm{Ti}_{2} \mathrm{O}_{3}$ & 6.7 & N 2.8 \\
\hline & \multirow[t]{2}{*}{ F 1s } & 688.2 & $\mathrm{C}-\mathrm{F}(0.2)$ & - & F 1.2 \\
\hline & & 685.3 & F complex/fluorides $(1.1)$ & & rest 3.4 \\
\hline
\end{tabular}

Table VI. Chemical Composition of the Oxide Layers Formed on the TNTZ Surface (After $168 \mathrm{~h}$ of Immersion in Artificial Saliva +1500 ppm $\mathbf{F}^{-}$)

\begin{tabular}{|c|c|c|c|c|c|}
\hline & Peak & BE Peak & Chemical State & Pct in Surface & At. Pct \\
\hline \multirow[t]{12}{*}{ Micro-TNTZ } & \multirow[t]{4}{*}{ Ti2p3 } & 458.7 & $\mathrm{TiO}_{2}$ & 38.7 & Ti 10.9 \\
\hline & & 453.4 & Ti metal & 3.8 & $\mathrm{Nb} 6.5$ \\
\hline & & 455.0 & $\mathrm{TiO}$ & 3.7 & Ta 2.4 \\
\hline & & 457.1 & $\mathrm{Ti}_{2} \mathrm{O}_{3}$ & 7.9 & $\operatorname{Zr} 0.3$ \\
\hline & \multirow[t]{2}{*}{$\mathrm{Nb} 3 \mathrm{~d} 5$} & 207.0 & $\mathrm{Nb}_{2} \mathrm{O}_{5}$ & 27.8 & O 40.5 \\
\hline & & 201.7 & $\mathrm{Nb}$ metal & 4.3 & C 26.2 \\
\hline & \multirow[t]{2}{*}{ Zr3d5 } & 182.1 & $\mathrm{ZrO}_{2}$ & 1.5 & F 8.0 \\
\hline & & 177.7 & $\mathrm{Zr}$ metal & 0.2 & Si 3.4 \\
\hline & \multirow[t]{2}{*}{ Ta4f7 } & 25.6 & $\mathrm{Ta}_{2} \mathrm{O}_{5}$ & 8.6 & N 1.7 \\
\hline & & 20.9 & Ta metal & 3.5 & \\
\hline & \multirow[t]{2}{*}{$\mathrm{F} 1 \mathrm{~s}$} & 688.6 & $\mathrm{C}-\mathrm{F}(7.4)$ & - & \\
\hline & & 685.2 & F complex/fluorides $(0.6)$ & - & \\
\hline \multirow[t]{12}{*}{ CR TNTZ } & \multirow[t]{4}{*}{ Ti2p3 } & 458.8 & $\mathrm{TiO}_{2}$ & 40.7 & Ti 12.5 \\
\hline & & 453.7 & Ti metal & 4.9 & $\mathrm{Nb} 7.3$ \\
\hline & & 455.8 & $\mathrm{TiO}$ & 4.3 & Ta 2.8 \\
\hline & & 457.2 & $\mathrm{Ti}_{2} \mathrm{O}_{3}$ & 4.3 & Zr 0.5 \\
\hline & \multirow[t]{2}{*}{$\mathrm{Nb} 3 \mathrm{~d} 5$} & 207.2 & $\mathrm{Nb}_{2} \mathrm{O}_{5}$ & 27.2 & O 43.4 \\
\hline & & 201.9 & $\mathrm{Nb}$ metal & 4.5 & C 27.3 \\
\hline & \multirow[t]{2}{*}{ Zr3d5 } & 182.3 & $\mathrm{ZrO}_{2}$ & 1.8 & F 2.4 \\
\hline & & 178.0 & Zr metal & 0.2 & Si 2.0 \\
\hline & \multirow[t]{2}{*}{ Ta4f7 } & 25.7 & $\mathrm{Ta}_{2} \mathrm{O}_{5}$ & 8.0 & N 1.7 \\
\hline & & 21.1 & Ta metal & 4.2 & \\
\hline & \multirow[t]{2}{*}{ F1s } & 688.8 & $\mathrm{C}-\mathrm{F}(2.1)$ & - & \\
\hline & & 685.0 & F complex/fluorides $(0.4)$ & - & \\
\hline
\end{tabular}

indicates increased passivity. ${ }^{[33,82]}$ The beneficial effect of grain refinement on the long-term corrosion response in biomedical solutions was also observed for Ti Grade 2 subjected to accumulative roll bonding (ARB). ${ }^{[26]}$ The growth of $R_{\mathrm{p}}$ value with the immersion time reported by Fattah-Alhosseini et al. ${ }^{[26]}$ was significantly greater for ARB-treated $\mathrm{Ti}$ than for its microcrystalline counterpart. The reason for the observed differences could derived from the effect of the high density of structural defects on $\mathrm{Ti}$ oxide layer evolution in the fluoridated medium (Tables III, V). XPS studies performed for the $\mathrm{CR}$ Ti revealed virtually no changes in the percentage amount of particular $\mathrm{Ti}$ oxides as well as metallic $\mathrm{Ti}$ after 168 hours of its immersion in fluoridated saliva (Tables III, V). Therefore, it can be assumed that the oxide layer formed on $\mathrm{CR} \mathrm{Ti}$ was stable during its immersion in the solution. For micro-Ti, the decrease of the amount of metallic Ti was observed after 168 hours of exposure to fluoridated medium. This indicates that the passive layer formed on its surface had the tendency to further growth (Tables III, V). It can be the reason of the corrosion resistance enhancement observed for micro-Ti after prolong exposure in the fluoridated saliva (Figure 9(d)). However, the passive layer which built-up 

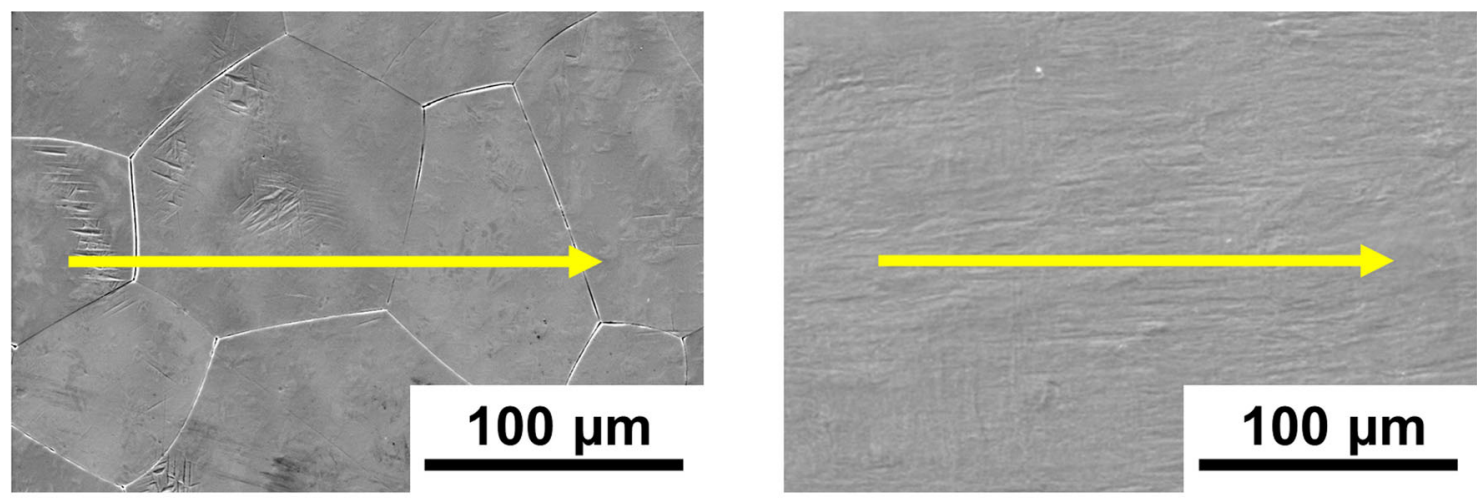

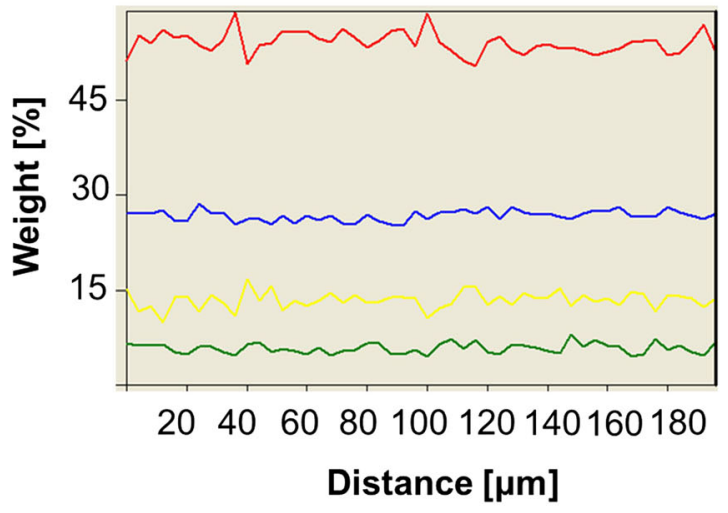

(a)

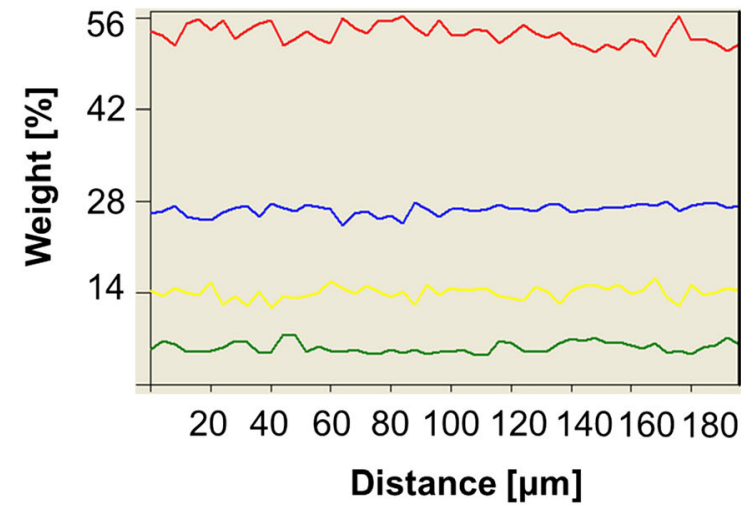

(b)

Fig. 7-Distribution of particular elements on the (a) micro-TNTZ and (b) CR TNTZ alloy surface (red line Ti, blue line Nb, yellow line Ta, green line $\mathrm{Zr}$ ) (Color figure online).

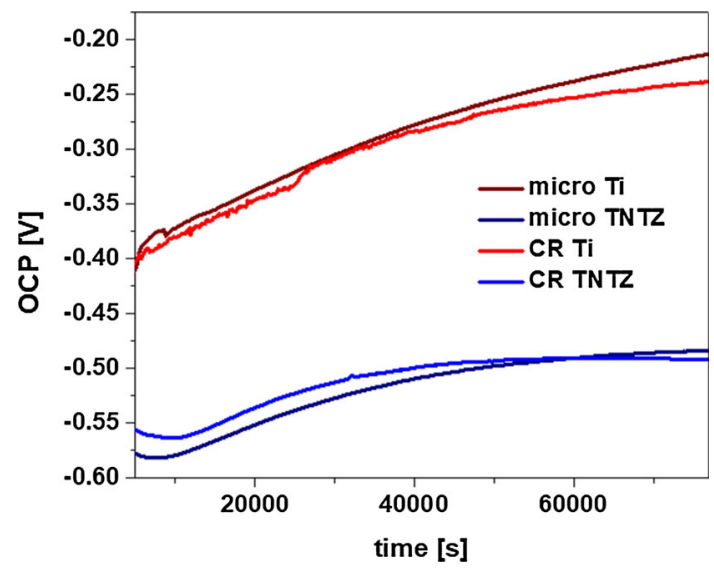

Fig. 8-Open circuit potential (OCP) evolution during $20 \mathrm{~h}$ of immersion in artificial saliva $+1500 \mathrm{ppm} \mathrm{F}^{-}$.

on the micro-Ti surface in the fluoridated solution could be more defective compared to the stable passive layer formed on CR Ti. This can explain better corrosion resistance observed for $\mathrm{CR} \mathrm{Ti}$. In contrast to $\mathrm{Ti}$, structural defects had no visible effect on the long-term corrosion response of TNTZ alloy. The $R_{\mathrm{p}}$ values designated for CR TNTZ and micro-TNTZ after longer immersion time were comparable (Figure 9(d)). Similar observations were reported for the $\mathrm{Ti}-24 \mathrm{Nb}-4 \mathrm{Zr}-8 \mathrm{Sn}$ alloy. In this case, the lack of influence of nanostructure on the corrosion response was observed in acidulated artificial saliva enriched with a relatively high concentration of fluorides (1000 $\left.\mathrm{ppm} \mathrm{F}^{-}\right) .^{[27]}$ Interestingly, irrespective of microstructure, TNTZ alloy did not demonstrate enhanced corrosion resistance to micro-Ti after 168 hours of immersion (Figures 9(b) and (d); Table VII). Hence, it can be assumed that the presence of the valve metals provides beneficial corrosion properties only in the case of short-term exposure to fluoride ions. During longer immersion times, corrosion resistance is governed mainly by the high number of structural defects. However, it have to be noticed that CR Ti demonstrated noticeably better corrosion properties compared to CR TNTZ. This indicates that the beneficial effect of structural defects is hindered by the presence of $\mathrm{Nb}_{2} \mathrm{O}_{5}, \mathrm{Ta}_{2} \mathrm{O}_{5}$, and $\mathrm{ZrO}_{2}$,

In order to confirm the conclusions drawn based on EIS data, additional PD tests were performed after 170 hours of materials immersion in the fluoridated artificial saliva (Figure 10(a)). Analysis of polarization curves revealed that for all of materials, the corrosion potential values $\left(E_{\text {corr }}\right)$ were in the range from -0.5 to $-0.1 \mathrm{~V} v s$. $\mathrm{Ag} / \mathrm{AgCl}$ electrode and the highest $E_{\text {corr }}$ value was found for CR Ti. For all of the samples, the current density was stabilized when the potential value exceeded about $+0.75 \mathrm{~V}$ vs. $\mathrm{Ag} / \mathrm{AgCl}$, and virtually no differences were revealed in the values of current density in the passive state (Figure 10(a)). To obtain a qualitative comparison 


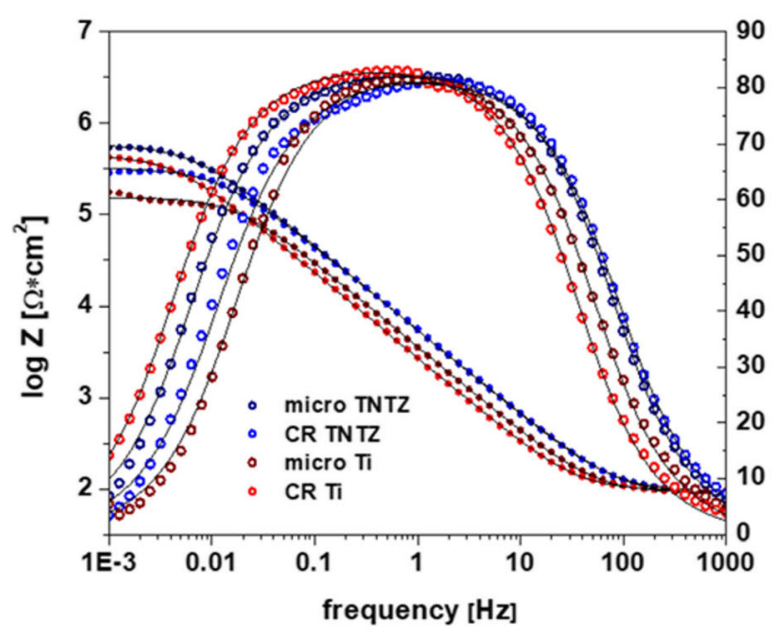

(a)

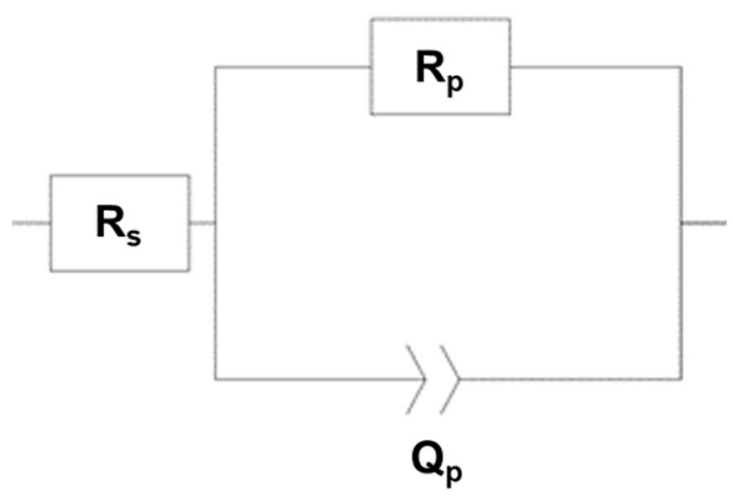

(c)

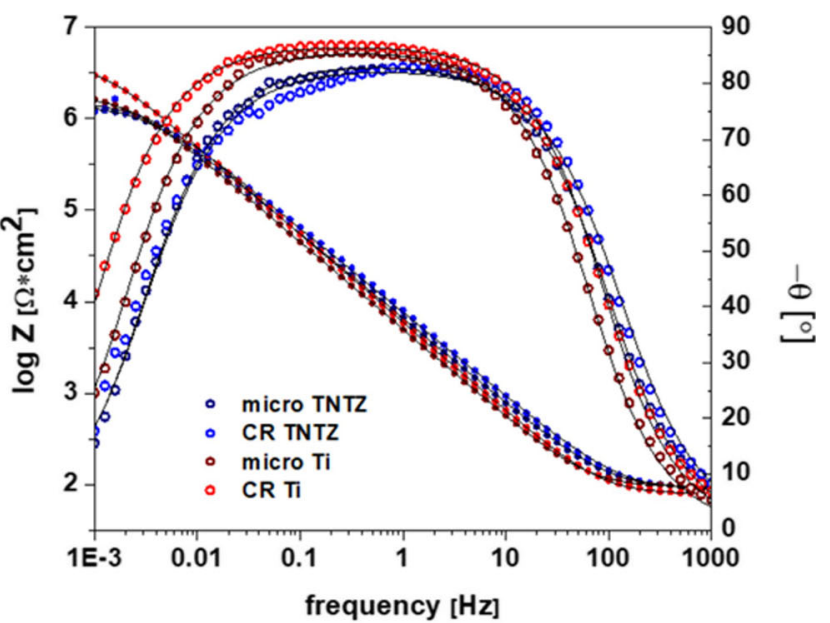

(b)

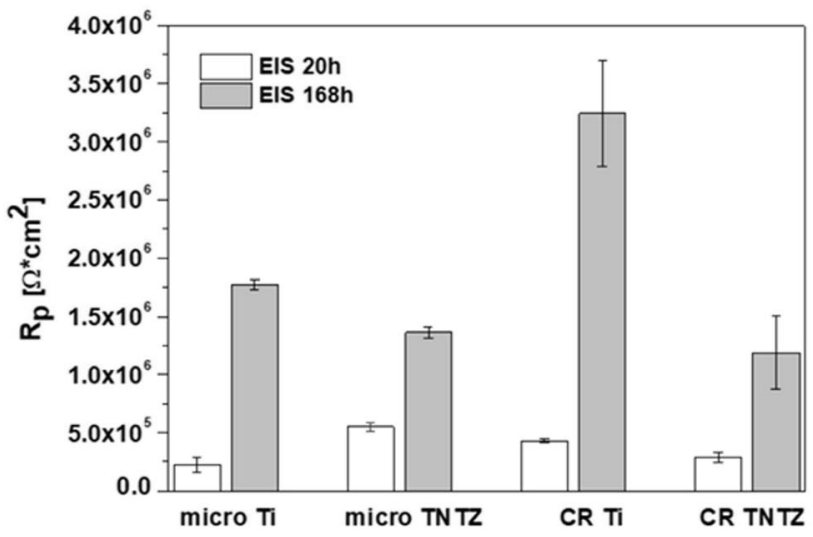

(d)

Fig. 9-EIS studies performed $(a) 20 \mathrm{~h}$ and $(b) 168 \mathrm{~h}$ after immersion in artificial saliva $+1500 \mathrm{ppm} \mathrm{F}^{-}$(simulated curves are marked as black lines), $(c)$ equivalent circuit used to designate values of electrochemical parameters, and $(d)$ charge transfer resistance designated from EIS data which corresponds to passive layer resistance.

Table VII. Electrochemical Parameters Designated From EIS Tests Performed After 20 and $168 \mathrm{~h}$ of Immersion in Artificial Saliva +1500 ppm F

\begin{tabular}{llccr}
\hline & & $R_{\mathrm{p}}\left(\mathrm{M} \Omega \mathrm{cm}^{2}\right)$ & $Y_{1}\left(\times 10^{-5} \Omega^{-1} \mathrm{~cm}^{-2} \mathrm{~s}^{\mathrm{n}}\right)$ & $n$ \\
\hline EIS $20 \mathrm{~h}$ & micro-Ti & $0.24 \pm 0.070$ & $6.11 \pm 0.091$ & 0.93 \\
& micro-TNTZ & $0.56 \pm 0.041$ & $3.76 \pm 0.041$ & 0.92 \\
& CR Ti & $0.49 \pm 0.021$ & $5.06 \pm 0.054$ & 0.94 \\
EIS $168 \mathrm{~h}$ & CR TNTZ & $0.30 \pm 0.053$ & $4.09 \pm 0.065$ & 0.92 \\
& micro-Ti & $1.76 \pm 0.055$ & $4.33 \pm 0.870$ & 0.95 \\
& micro-TNTZ & $1.35 \pm 0.050$ & $2.97 \pm 0.210$ & 0.92 \\
& CR Ti & $3.22 \pm 0.461$ & $3.53 \pm 0.235$ & 0.91 \\
\hline
\end{tabular}

of the PD and EIS data, the polarization resistance $\left(R_{\text {pol }}\right)$ was designated by extrapolating the cathodic and anodic branches of the polarization curves (Tafel constants $\left|b_{\mathrm{c}}\right|=0.02$ to 0.03 and $\left|b_{\mathrm{a}}\right|=0.06$ to 0.08 ) in the vicinity of the corrosion potential $\left(E_{\text {corr }} \pm 20 \mathrm{mV}\right)$. $R_{\text {pol }}$ values demonstrated a similar trend to $R_{\mathrm{p}}$ which confirmed that the oxide layer formed on the surface of CR Ti had the most protective properties (Figure 10(b)).

\section{SUMMARY AND CONCLUSIONS}

This study presents a comparative evaluation of the surface and mechanical properties of $\alpha$ and $\beta$-phased Ti materials such as Ti Grade 2 and TNTZ alloy in terms of their dental applications. The differences observed were explained based on the microstructure and surface chemical composition analysis. The results obtained in this work were as follows: 


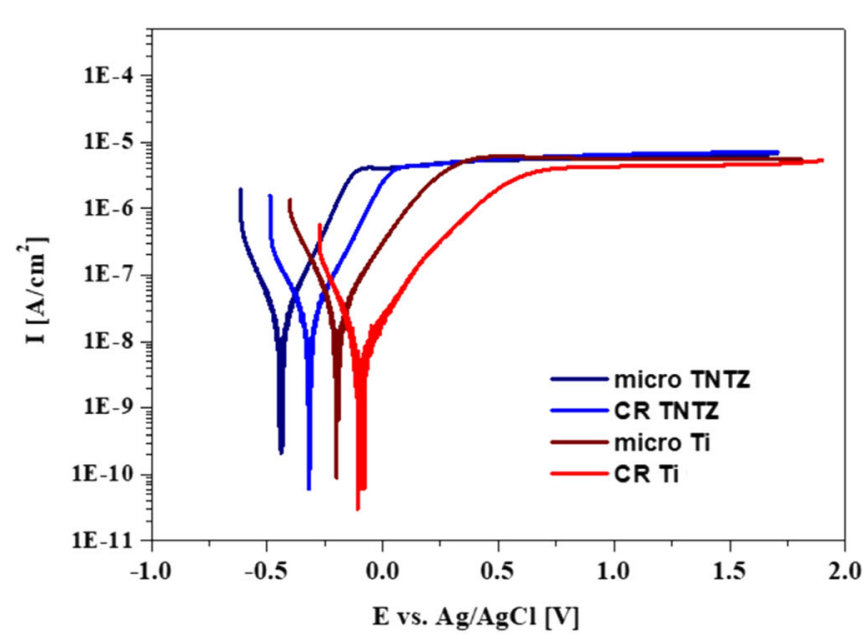

(a)

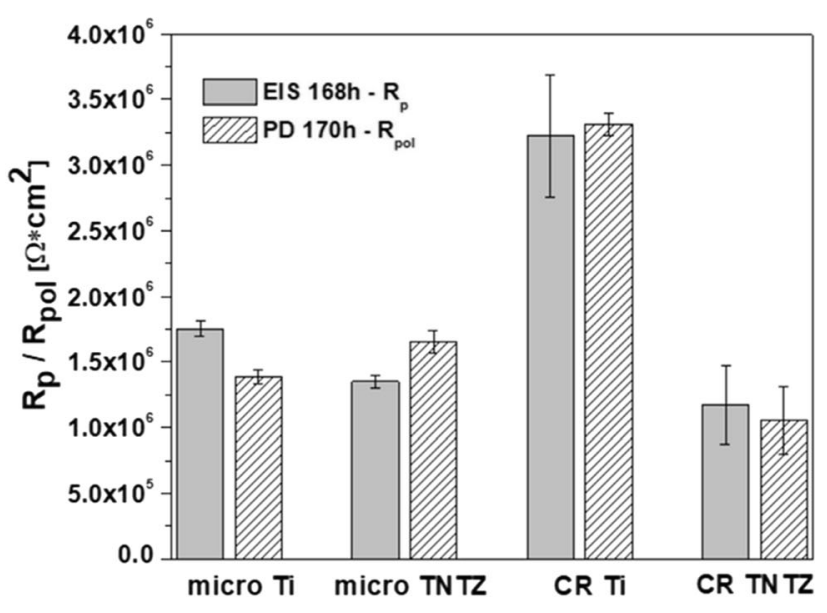

(b)

Fig. 10-Results of potentiodynamic measurements $(a)$ polarization curves recorded $170 \mathrm{~h}$ after immersion in artificial saliva +1500 ppm $\mathrm{F}^{-}$, and $(b)$ a comparison of polarization resistance $R_{\text {pol }}$ and passive layer resistance $R_{\mathrm{p}}$ designated from PD and EIS data respectively.

1. Multiple-pass cold rolling resulted in significant strengthening (93 and 41 pct increase of UTS for Ti Grade 2 and TNTZ, respectively). The greater increase of UTS reported for Ti Grade 2 could be associated with the large fraction of transverse dislocation boundaries in CR Ti which create more difficulties for dislocation slip. Additionally, texture evolution during the cold-rolling of TNTZ resulted in the reduction of the elastic modulus value, which is beneficial in terms of dental applications.

2. The susceptibility of the oxide layers to fluoride-induced attack depends on the combined effect of the presence of valve alloying elements and the high density of structural defects. The addition of $\mathrm{Nb}$, $\mathrm{Ta}$, and $\mathrm{Zr}$ stabilizes the oxide layer formed on $\mathrm{Ti}$ surface and thereby enhances corrosion resistance in the shorter immersion time. However, this beneficial effect is countered to a certain extent by the large fraction of structural defects.

3. A large number of structural defects increased the passive layer resistance in case of pure Ti after both shorter (20 hours) and longer (168 hours) immersion time in the fluoridated saliva. However, this effect was the most pronounced for prolong exposure to fluoride-rich solution.

4. Both valve alloying elements and the high density of structural defects enhance the corrosion resistance of pure $\mathrm{Ti}$ materials in case of shorter exposure times to fluoridated medium. However, these factors do not act in a synergistic manner. This aspect should be factored in during future design of modern dental materials. Although there is no doubt that multiple-pass cold rolling enhance the mechanical strength of Ti-based materials, the influence of this process is not straightforward in terms of surface properties in the aggressive conditions found in the oral cavity.

\section{ACKNOWLEDGMENTS}

This work was financially supported by the National Science Centre in Poland (Grant Number: 2016/21/B/ ST8/01965). The authors would also like to thank PhD Witold Chromiński for performing EBSD analysis.

\section{CONFLICT OF INTEREST}

On behalf of all authors, the corresponding author states that there is no conflict of interest.

\section{OPEN ACCESS}

This article is licensed under a Creative Commons Attribution 4.0 International License, which permits use, sharing, adaptation, distribution and reproduction in any medium or format, as long as you give appropriate credit to the original author(s) and the source, provide a link to the Creative Commons licence, and indicate if changes were made. The images or other third party material in this article are included in the article's Creative Commons licence, unless indicated otherwise in a credit line to the material. If material is not included in the article's Creative Commons licence and your intended use is not permitted by statutory regulation or exceeds the permitted use, you will need to obtain permission directly from the copyright holder. To view a copy of this licence, visit http://creat ivecommons.org/licenses/by/4.0/.

\section{REFERENCES}

1. Ş. Çallığlu and P. Acar: Mater. Sci. Eng. C, 2020, vol. 110, p. 110715 .

2. L. Zhang and L. Chen: Adv. Eng. Mater., 2019, vol. 21, p. 1801215 . 
3. S. Acharya, S. Mishra, K.U. Yazar, K. Chatterjee, and S. Suwas: Metall. Mater. Trans. A, 2020, vol. 51A, pp. 4045-58.

4. K. Ozaltin, A. Panigrahi, W. Chrominski, A.G. Bulutsuz, M. Kulczyk, M.J. Zehetbauer, and M. Lewandowska: Metall. Mater. Trans. A, 2017, vol. 48A, pp. 5747-55.

5. F. Haftlang, A. Zarei-Hanzaki, and H.R. Abedi: Mater. Sci. Eng. C, 2020, vol. 109 , p. 110561 .

6. D. Kuczyńska-Zemła, E. Kijeńska-Gawrońska, A. Chlanda, A. Sotniczuk, M. Pisarek, K. Topolski, W. Swieszkowski, and H. Garbacz: Appl. Surf. Sci., 2020, vol. 511, p. 145523.

7. M. Niinomi: J. Biomed. Mater. Res. A, 2019, vol. 107, pp. 944-54.

8. C. Vasilescu, S.I. Drob, P. Osiceanu, J.M.C. Moreno, M. Prodana, D. Ionita, I. Demetrescu, M. Marcu, I.A. Popovici, and E. Vasilescu: Metall. Mater. Trans. A, 2017, vol. 48A, pp. 513-23.

9. H. Miyamoto: Mater. Trans., 2016, vol. 575, pp. 559-72.

10. S.F. Jawed, C.D. Rabadia, Y.J. Liu, L.Q. Wang, P. Qin, Y.H. Li, X.H. Zhang, and L.C. Zhang: Mater. Sci. Eng. C, 2020, vol. 110, p. 110728.

11. C.N. Elias, D.J. Fernandes, F.M. De Souza, E.D.S. Monteiro, and R.S. De Biasi: J. Mater. Res. Technol., 2019, vol. 8, pp. 1060-69.

12. T. Krajňák, M. Janeček, P. Minárik, J. Veselý, P. Cejpek, J. Gubicza, P.T. Hung, D. Preisler, F. Nový, and A.G. Raab: Metall. Mater. Trans. A, 2021, vol. 52A, pp. 1-14.

13. A.R.V. Nunes, S. Borborema, L.S. Araújo, L. Malet, J. Dille, and L.H. de Almeida: J. Alloys Compd., 2020, vol. 820, p. 153078.

14. S. Bahl, S. Suwas, and K. Chatterjee: Int. Mater. Rev., 2020, vol. 66, pp. 114-39.

15. I. Caha, A. Alves, C. Chirico, A. Pinto, S. Tsipas, E. Gordo, and F. Toptan: Metall. Mater. Trans. A, 2020, vol. 51A, pp. 3256-67.

16. H. Yilmazer, M. Niinomi, M. Nakai, J. Hieda, Y. Todaka, T. Akahori, and T. Miyazaki: J. Mech. Behav. Biomed. Mater., 2012, vol. 10, pp. 235-45.

17. M. Niinomi, M. Nakai, and J. Hieda: Acta Biomater., 2012, vol. 8, pp. 3888-3903.

18. M. Kheradmandfard, S.F. Kashani-Bozorg, K.-H. Kang, O.V. Penkov, A.Z. Hanzaki, Y.-S. Pyoun, A. Amanov, and D.-E. Kim: J. Alloys Compd., 2018, vol. 738, pp. 540-49.

19. M. Ebrahimi and S. Attarilar: Metall. Mater. Trans. A, 2021, vol. 52, pp. 1-11.

20. A. Sotniczuk and H. Garbacz: Adv. Eng. Mater., 2021, vol. 23, p. 2000909.

21. R.Z. Valiev, E.V. Parfenov, and L.V. Parfenova: Mater. Trans., 2019, vol. 60, pp. 1356-66.

22. K. Sharman, P. Bazarnik, T. Brynk, A.G. Bulutsuz, M. Lewandowska, Y. Huang, and T.G. Langdon: J. Mater. Res. Technol., 2015, vol. 4, pp. 79-83.

23. M.J. Qarni, G. Sivaswamy, A. Rosochowski, and S. Boczkal: Mater. Des., 2017, vol. 122, pp. 385-402.

24. N. Nayan, G. Singh, T.A. Prabhu, S.V.S.N. Murty, and U. Ramamurty: Metall. Mater. Trans. A, 2018, vol. 49A, pp. 128-46.

25. S. Ozan, J. Lin, W. Weng, Y. Zhang, Y. Li, and C. Wen: Bioact. Mater., 2019, vol. 4, pp. 303-11.

26. A. Fattah-Alhosseini, A.R. Ansari, Y. Mazaheri, and M.K. Keshavarz: Mater. Sci. Eng. C, 2017, vol. 71, pp. 771-79.

27. J. Li, Y. Bai, Z. Fan, S. Li, Y. Hao, R. Yang, and Y. Gao: $J$. Mater. Sci. Technol., 2018, vol. 34, pp. 1660-70.

28. K.D. Ralston and N. Birbilis: Corrosion, 2010, vol. 66, p. 75005.

29. H. Miyamoto, M. Yuasa, M. Rifai, and H. Fujiwara: Mater. Trans., 2019, vol. 60, pp. 1243-55.

30. D.M. Brunette, P. Tengvall, M. Textor, and P. Thomsen: Titanium in Medicine: Material Science, Surface Science, Engineering, Biological Responses and Medical Applications, Springer, Berlin, 2012.

31. A. Chojnacka, J. Kawalko, H. Koscielny, J. Guspiel, A. Drewienkiewicz, M Bieda, W Pachla, M. Kulczyk, K. Sztwiertnia, and E. Beltowska-Lehman: Appl. Surf. Sci., 2017, vol. 426 , pp. $987-94$

32. I. Dimić, I. Cvijović-Alagić, B. Völker, A. Hohenwarter, R. Pippan, D. Veljović, M. Rakin, and B. Bugarski: Mater. Des., 2016, vol. 91, pp. 340-47.

33. A. Fattah-Alhosseini, O. Imantalab, and G. Ansari: Mater. Sci. Eng. C, 2017, vol. 71, pp. 827-34.

34. M.F. Ijaz, Y. Zhukova, A. Konopatsky, S. Dubinskiy, A. Korobkova, Y. Pustov, V. Brailovski, and S. Prokoshkin: J. Alloys Compd., 2018, vol. 748, pp. 51-56.
35. I. Cvijović-Alagić, Z. Cvijović, S. Mitrović, V. Panić, and M. Rakin: Corros. Sci., 2011, vol. 53, pp. 796-808.

36. J.D.C. Tardelli, C. Bolfarini, and A.C. Dos Reis: J. Trace Elem. Med. Biol., 2020, vol. 62, p. 126618.

37. Z.B. Wang, H.X. Hu, C.B. Liu, and Y.G. Zheng: Electrochim. Acta, 2014, vol. 135, pp. 526-35.

38. X. Chen, K. Shah, S. Dong, L. Peterson, E.C. La Plante, and G. Sant: Dent. Mater., 2020, vol. 36, pp. 431-41.

39. G. Peñarrieta-Juanito, M.B. Sordi, B. Henriques, M.E.R. Dotto, W. Teughels, F.S. Silva, R.S. Magini, and J.C.M. Souza: J. Periodontal Res., 2019, vol. 54, pp. 46-52.

40. Y. Li and J. Xu: Electrochim. Acta, 2017, vol. 233, pp. 151-66.

41. H.-H. Huang: Biomaterials, 2003, vol. 24, pp. 275-82.

42. T. Wejrzanowski, M. Lewandowska, and K.J. Kurzydłowski: Image Anal. Stereol., 2010, vol. 29, pp. 1-12.

43. K. Majchrowicz, Z. Pakieła, T. Brynk, B. Romelczyk-Baishya, M. Płocińska, T. Kurzynowski, and E. Chlebus: Mater. Sci. Eng. $A$, 2019, vol. 765 , p. 138290 .

44. R.M. Molak, M.E. Kartal, Z. Pakiela, and K.J. Kurzydlowski: Mater. Sci. Eng. A, 2016, vol. 651, pp. 810-21.

45. T. Brynk, R.M. Molak, M. Janiszewska, and Z. Pakiela: Comput. Mater. Sci., 2012, vol. 64, pp. 157-61.

46. J.-Y. Gal, Y. Fovet, and M. Adib-Yadzi: Talanta, 2001, vol. 53, pp. 1103-15.

47. E. Newbrun: J. Dent. Educ., 2001, vol. 65, pp. 1078-83.

48. D.K. Yang, P. Cizek, P.D. Hodgson, and C.E. Wen: Acta Mater., 2010, vol. 58, pp. 4536-48.

49. S.V. Zherebtsov, G.S. Dyakonov, A.A. Salem, S.P. Malysheva, G.A. Salishchev, and S.L. Semiatin: Mater. Sci. Eng. A, 2011, vol. 528 , pp. $3474-79$

50. C. Lan, Y. Wu, L. Guo, and F. Chen: Mater. Sci. Eng. A, 2017, vol. 690 , pp. $170-76$.

51. K. Ozaltin, W. Chrominski, M. Kulczyk, A. Panigrahi, J. Horky, M. Zehetbauer, and M. Lewandowska: J. Mater. Sci., 2014, vol. 49, pp. 6930-36.

52. Y. Wang, J. Zhao, S. Dai, F. Chen, X. Yu, and Y. Zhang: J. Mech. Behav. Biomed. Mater., 2013, vol. 27, pp. 33-42.

53. H. Matsumoto, S. Watanabe, and S. Hanada: J. Alloys Compd., 2007, vol. 439, pp. 146-55.

54. V.D. Cojocaru, D. Raducanu, T. Gloriant, D.M. Gordin, and I. Cinca: Mater. Sci. Eng. A, 2013, vol. 586, pp. 1-10.

55. A. Fattah-Alhosseini, A. Reza Ansari, Y. Mazaheri, M. Karimi, and M. Haghshenas: Mater. Sci. Eng. A, 2017, vol. 688, pp. 218-24.

56. M. Niinomi, Y. Liu, M. Nakai, H. Liu, and H. Li: Regen. Biomater., 2016, vol. 3, pp. 173-85.

57. J. Gao, Y. Huang, D. Guan, A.J. Knowles, L. Ma, D. Dye, and W.M. Rainforth: Acta Mater., 2018, vol. 152, pp. 301-14.

58. D. Kuhlmann-Wilsdorf: Mater. Sci. Eng. A, 1989, vol. 113, pp. $1-41$.

59. A.R.V. Nunes, S. Borborema, L.S. Araujo, J. Dille, L. Malet, and L.H. de Almeida: J. Alloys Compd., 2018, vol. 743, pp. 141-45.

60. C. Lan, Y. Wu, L. Guo, H. Chen, and F. Chen: J. Mater. Sci. Technol., 2018, vol. 34, pp. 788-92.

61. M. Tane, S. Akita, T. Nakano, K. Hagihara, Y. Umakoshi, M. Niinomi, and H. Nakajima: Acta Mater., 2008, vol. 56, pp. 2856-63.

62. S. Ozan, J. Lin, Y. Zhang, Y. Li, and C. Wen: J. Mater. Res. Technol., 2020, vol. 9, pp. 2308-18.

63. K. Topolski, T. Brynk, and H. Garbacz: Arch. Civ. Mech. Eng., 2016, vol. 16, pp. 927-34.

64. A.E. Medvedev, A. Neumann, H.P. Ng, R. Lapovok, C. Kasper, T.C. Lowe, V.N. Anumalasetty, and Y. Estrin: Mater. Sci. Eng. C, 2017, vol. 71, pp. 483-97.

65. Y. Gu, A. Ma, J. Jiang, H. Li, D. Song, H. Wu, and Y. Yuan: Mater. Charact., 2018, vol. 138, pp. 38-47.

66. H. Garbacz, M. Pisarek, and K.J. Kurzydłowski: Biomol. Eng., 2007, vol. 24 , pp. $559-63$

67. J. Lu, Y. Zhang, W. Huo, W. Zhang, Y. Zhao, and Y. Zhang: Appl. Surf. Sci., 2018, vol. 434, pp. 63-72.

68. A. Stájer, K. Ungvári, I.K. Pelsőczi, H. Polyánka, A. Oszkó, E. Mihalik, Z. Rakonczay, M. Radnai, L. Kemény, and A. Fazekas: J. Biomed. Mater. Res. A, 2008, vol. 87, pp. 450-58.

69. Y.J. Bai, Y.B. Wang, Y. Cheng, F. Deng, Y.F. Zheng, and S.C. Wei: Mater. Sci. Eng. C, 2011, vol. 31, pp. 702-11. 
70. I. Caha, A.C. Alves, P.A.B. Kuroda, C.R. Grandini, A.M.P. Pinto, L.A. Rocha, and F. Toptan: Corros. Sci., 2020 , vol. 167, p. 108488.

71. N.T.C. Oliveira and A.C. Guastaldi: Acta Biomater., 2009, vol. 5, pp. 399-405.

72. J. Lu, Y. Zhao, H. Niu, Y. Zhang, Y. Du, W. Zhang, and W. Huo: Mater. Sci. Eng. C, 2016, vol. 62, pp. 36-44.

73. D. Mareci, R. Chelariu, D.-M. Gordin, G. Ungureanu, and T. Gloriant: Acta Biomater., 2009, vol. 5, pp. 3625-39.

74. I. Milošev, B. Kapun, and V.S. Šelih: Acta Chim. Slov., 2013, vol. 60 , pp. $543-55$.

75. P.F. Ji, B. Li, B.H. Chen, F. Wang, W. Ma, X.Y. Zhang, M.Z. Ma, and R.P. Liu: Corros. Sci., 2020, vol. 170, art. no. 108696.

76. Z. Jiang, X. Dai, T. Norby, and H. Middleton: Corros. Sci., 2011, vol. 53, pp. 815-21.
77. I. Milošev, T. Kosec, and H.-H. Strehblow: Electrochim. Acta, 2008, vol. 53, pp. 3547-58.

78. M.-K. Han, M.-J. Hwang, M.-S. Yang, H.-S. Yang, H.-J. Song, and Y.-J. Park: Mater. Sci. Eng. A, 2014, vol. 616, pp. 268-74.

79. S. Acharya, A.G. Panicker, D.V. Laxmi, S. Suwas, and K. Chatterjee: Mater. Des., 2019, vol. 164, p. 107555

80. R. Huang and Y. Han: Mater. Sci. Eng. C, 2013, vol. 33, pp. 2353-59.

81. J. Li, S.J. Li, Y.L. Hao, H.H. Huang, Y. Bai, Y.Q. Hao, Z. Guo, J.Q. Xue, and R. Yang: Acta Biomater., 2014, vol. 10, pp. 2866-75.

82. A. Sotniczuk, D. Kuczyńska-Zemła, A. Królikowski, and H. Garbacz: Corros. Sci., 2019, vol. 147, pp. 342-49.

Publisher's Note Springer Nature remains neutral with regard to jurisdictional claims in published maps and institutional affiliations. 